\title{
Unraveling the structure and function of CdcPDE: A novel phosphodiesterase from Crotalus durissus collilineatus snake venom
}

\begin{abstract}
de Oliveira, Isadora Sousa; Pucca, Manuela Berto; Wiezel, Gisele Adriano; Cardoso, lara Aimê; de Castro Figueiredo Bordon, Karla; Sartim, Marco Aurélio; Kalogeropoulos, Konstantinos; Ahmadi, Shirin; Baiwir, Dominique; Nonato, Maria Cristina
\end{abstract}

Total number of authors:

15

Published in:

International Journal of Biological Macromolecules

Link to article, DOI:

10.1016/j.ijbiomac.2021.02.120

Publication date:

2021

Document Version

Peer reviewed version

Link back to DTU Orbit

Citation (APA):

de Oliveira, I. S., Pucca, M. B., Wiezel, G. A., Cardoso, I. A., de Castro Figueiredo Bordon, K., Sartim, M. A., Kalogeropoulos, K., Ahmadi, S., Baiwir, D., Nonato, M. C., Sampaio, S. V., Laustsen, A. H., auf dem Keller, U., Quinton, L., \& Arantes, E. C. (2021). Unraveling the structure and function of CdcPDE: A novel phosphodiesterase from Crotalus durissus collilineatus snake venom. International Journal of Biological Macromolecules, 178, 180-192. https://doi.org/10.1016/j.ijbiomac.2021.02.120

\section{General rights}

Copyright and moral rights for the publications made accessible in the public portal are retained by the authors and/or other copyright owners and it is a condition of accessing publications that users recognise and abide by the legal requirements associated with these rights.

- Users may download and print one copy of any publication from the public portal for the purpose of private study or research.

- You may not further distribute the material or use it for any profit-making activity or commercial gain

- You may freely distribute the URL identifying the publication in the public portal 


\section{Journal Pre-proof}

Unraveling the structure and function of CdcPDE: A novel phosphodiesterase from Crotalus durissus collilineatus snake venom

Isadora Sousa de Oliveira, Manuela Berto Pucca, Gisele Adriano Wiezel, Iara Aimê Cardoso, Karla de Castro Figueiredo Bordon, Marco Aurélio Sartim, Konstantinos Kalogeropoulos, Shirin Ahmadi, Dominique Baiwir, Maria Cristina Nonato, Suely Vilela

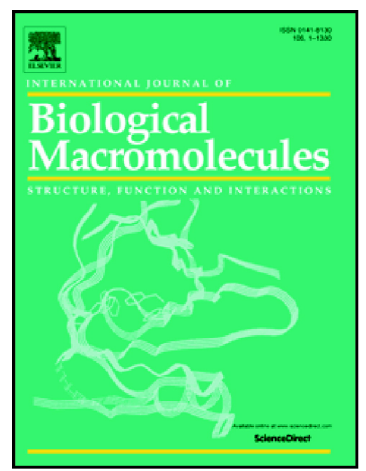
Sampaio, Andreas Hougaard Laustsen, Ulrich auf dem Keller, Loïc Quinton, Eliane Candiani Arantes

PII: $\quad$ S0141-8130(21)00399-8

DOI: $\quad$ https://doi.org/10.1016/j.ijbiomac.2021.02.120

Reference: $\quad$ BIOMAC 17947

To appear in: $\quad$ International Journal of Biological Macromolecules

Received date: $\quad 11$ December 2020

Revised date: $\quad 13$ February 2021

Accepted date: $\quad 15$ February 2021

Please cite this article as: I.S. de Oliveira, M.B. Pucca, G.A. Wiezel, et al., Unraveling the structure and function of CdcPDE: A novel phosphodiesterase from Crotalus durissus collilineatus snake venom, International Journal of Biological Macromolecules (2018), https://doi.org/10.1016/j.ijbiomac.2021.02.120

This is a PDF file of an article that has undergone enhancements after acceptance, such as the addition of a cover page and metadata, and formatting for readability, but it is not yet the definitive version of record. This version will undergo additional copyediting, typesetting and review before it is published in its final form, but we are providing this version to give early visibility of the article. Please note that, during the production process, errors may be discovered which could affect the content, and all legal disclaimers that apply to the journal pertain. 
(C) 2018 Published by Elsevier. 
Unraveling the structure and function of $C d c$ PDE: A novel phosphodiesterase from Crotalus durissus collilineatus snake venom

Isadora Sousa de Oliveira ${ }^{\mathrm{a}}$, Manuela Berto Pucca ${ }^{\mathrm{b}}$, Gisele Adriano Wiezel ${ }^{\mathrm{a}}$, Iara Aimê Cardoso ${ }^{\mathrm{a}}$, Karla de Castro Figueiredo Bordon ${ }^{\mathrm{a}}$, Marco Aurélio Sartim ${ }^{\mathrm{c}, \mathrm{d}}$, Konstantinos Kalogeropoulos ${ }^{\mathrm{e}}$, Shirin Ahmadi $^{\mathrm{e}}$, Dominique Baiwir ${ }^{\mathrm{f}, \mathrm{g}}$, Maria Cristina Nonato ${ }^{\mathrm{a}}$, Suely Vilela Sampaio ${ }^{\mathrm{h}}$, Andreas Hougaard Laustsen $^{\mathrm{e}}$, Ulrich auf dem Keller ${ }^{\mathrm{e}}$, Loïc Quinton ${ }^{\mathrm{f}}$, Eliane Candiani Arantes ${ }^{\mathrm{a}, *}$

${ }^{a}$ Department of BioMolecular Sciences, School of Pharmaceutiral Sciences of Ribeirão Preto, University of São Paulo, Ribeirão Preto, SP, Brazil

${ }^{\mathrm{b}}$ Medical School, Federal University of Roraima, Boa Vista, RR Brc zil

${ }^{\mathrm{c}}$ Institute of Biological Sciences, Federal University of Am ızo ‘as, Manaus, AM, Brazil

${ }^{\mathrm{d}}$ Department of Teaching and Research, Dr. Heitor ${ }^{r_{i}}$ eira Lourado Tropical Medicine Foundation, Manaus, AM, Brazil.

e Department of Biotechnology and Biomedicint, Technical University of Denmark, Kongens Lyngby, Denmark

${ }^{\mathrm{f}}$ Mass Spectrometry Laboratory, Dex rtmı nt of Chemistry, University of Liège, Liège, Belgium ${ }^{\mathrm{g}}$ GIGA Proteomics Facility, Unive - ity of Liège, Liège, Belgium

${ }^{\mathrm{h}}$ Department of Clinical Anc'ysis, Toxicology and Food Science, School of Pharmaceutical Sciences of Ribeirão Preto, University of jão Paulo, Ribeirão Preto, SP, Brazil

\section{*Corresponding author}

Dr. Eliane Candiani Arantes, Laboratory of Animal Toxins, Department of BioMolecular Sciences, School of Pharmaceutical Sciences of Ribeirão Preto, University of São Paulo. Av. do Café s/nº, Monte Alegre, 14040-903 - Ribeirão Preto, SP - Brazil, Phone: +55 (16) 33154275, Fax: +55 (16) 33154880, e-mail: ecabraga@fcfrp.usp.br.

\section{Abstract}


This study reports the isolation, structural, biochemical, and functional characterization of a novel phosphodiesterase from Crotalus durissus collilineatus venom (CdcPDE). CdcPDE was successfully isolated from whole venom using three chromatographic steps and represented $0.7 \%$ of total protein content. $C d c$ PDE was inhibited by EDTA and reducing agents, demonstrating that metal ions and disulfide bonds are necessary for its enzymatic activity. The highest enzymatic activity was observed at pH 8-8.5 and $37^{\circ} \mathrm{C}$. Kinetic parameters indicated a higher affinity for the substrate bis(p-nitrophenyl) phosphate compared to others snake venom PDEs. Its structural sharacterization was done by the determination of the protein primary sequence by Edman degra $\left.\lrcorner a t_{\iota}\right\urcorner n$ and mass spectrometry, and completed by the building of molecular and docking-based mo lels Functional in vitro assays showed that $C d c \mathrm{PDE}$ is capable of inhibiting platelet aggregation na sed by adenosine diphosphate in a dosedependent manner and demonstrated that $C d c \mathrm{PDE}$ is cviotoxic to human keratinocytes. $C d c \mathrm{PDE}$ was recognized by the crotalid antivenom producer hy the Instituto Butantan. These findings demonstrate that the study of snake venom toxins can reval new molecules that may be relevant in cases of snakebite envenoming, and that can be $1 \mathrm{~S}$. $\mathcal{A}$ as molecular tools to study pathophysiological processes due to their specific biological activit es.

Keywords: Crotalus durissus colli.'ineatus; phosphodiesterase; cytotoxicity.

\section{Introduction}

Snakebite envenomirg is recognized as a Neglected Tropical Disease (NTD) by the World Health Organization (WHO) due to its high level of morbidity and mortality, as well as its frequency in impoverished regions of the tropics [1-5]. In Brazil, 30,000 snakebite envenomings are reported each year, primarily caused by four genera, Micrurus, Bothrops, Lachesis, and Crotalus [6], being the last one represented by six subspecies, $C$. durissus collilineatus, $C$. $d$. terrificus, $C$. $d$. marajoensis, $C . d$. ruruima, C. d. cascavella, and C. d. durissus [7].

Crotalid venoms contain proteins with enzymatic and non-enzymatic activities [8,9]. Nucleases are among the enzymatic components that are able to hydrolyze nucleic acids and their derivates [10], 
which can be subdivided into endonucleases [11] (DNAse [12] and RNAse [13]) and exonucleases, which include phosphodiesterases (PDE) [14]. PDEs are metalloglycoproteins [15-17] with high molecular mass (90 kDa $160 \mathrm{kDa}$ ), found in the monomeric, homodimeric, or heterodimeric forms [17-22], which can hydrolyze phosphodiester bonds of polynucleotides in basic $\mathrm{pH}$, starting at the 3'extremity, resulting in 5'-mononucleotides [10]. In addition, PDEs can hydrolyze adenosine triphosphate (ATP) and adenosine diphosphate (ADP) to produce adenosine $[10,18]$, nicotinamide adenine (NAD), and nicotinamide guanine dinucleotide (NGD) [10], as well as second messengers, such as 3',5'-cyclic adenosine monophosphate (cAMP), and 3',5-c, shc guanosine monophosphate (cGMP) [23]. Due to their functionality, PDEs can play an imp rtant role in many physiological processes, including muscle contraction, cell different atı $\mathrm{n}$, ion channel function, lipogenesis, gluconeogenesis, glycogenolysis, and apoptosis [24-24], may be considered as potential therapeutic candidates for treating different diseases su $^{\text {hh }}$ a cardiovascular, inflammatory, and Alzheimer's diseases, as well as erectile dysfunction [25-30].

PDEs are classified into eleven types (D)1-11) according to their inhibitor-sensitivity, protein sequence, pharmacological propertie: anci substrate specificity. PDE4, 7, and 8 are specific for cAMP degradation, whereas PDE5, 6, an' $y$ are specific for cGMP degradation, and PDE1, 2, 3, 10, and 11 for degrade both cAMP and GN P [31,32].

Proteomic and transcriptornir data indicate that PDEs are found in several snake venoms [33-37], but in low abundance [38], and despite the wide distribution across different snake families, the role of these enzymes in snakebite envenoming has not been adequately explored [10]. Russell, Buess, and Woo (1963) partially purified the PDEs present in C. adamanteus, C. atrox, C. viridis helleri, $C$. horridus, and Vipera russelli venoms, reporting that PDEs were able to lead to hypotensive crisis in animals, characterized by low blood pressure and locomotor depression due to cAMP depletion [39]. This hypotensive effect of snake PDEs indicates that PDE substrates are available in the circulatory system of snakebite victims $[10,40]$. 
Since the discovery of PDEs in snake venoms (1932) [14], they have been used in nucleic acid characterization and as molecular biology tools [19]. They can act as platelet aggregation inhibitors $[26,41,42]$ and may, eventually, become potential drug leads to treat dysfunctions related to increased platelet aggregation (e.g. thrombosis) [42].

Among nucleases, PDEs are relatively well-characterized; however, compared to other snake venom components, such as phospholipases, and serine and metalloproteases, studies focusing on PDEs are relatively rare. Here, we report the isolation, and structural and funrtional characterization of a novel PDE from $C . d$. collilineatus venom $(C d c \mathrm{PDE})$, and showcase its s onl $\mathrm{v}$ to inhibit platelet aggregation and induce cytotoxicity on human keratinocytes.

\section{Methods}

\subsection{Venom fractionation and $C d c$ PDE purification}

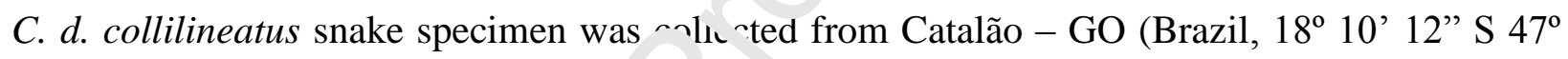
$56^{\prime} 31$ ” W) and kept in the Serpentarium of L. University of São Paulo at Ribeirão Preto Medical School. Its venom was milked by compr $-S_{i}$ : on of venom glands, dried in a glass vacuum desiccator for 6 hours at room temperature (RT) ai 1 stcied at $-20{ }^{\circ} \mathrm{C}$ until usage. This Serpentarium is accredited by the Instituto Brasileiro do Meio A. Điente e dos Recursos Naturais Renováveis (Brazilian Institute of Environment and Renewablc Nai Iral Resources), under the registration number 1506748.

Dried venom $(90 \mathrm{mc}$ ) was resuspended in $50 \mathrm{mM}$ Tris- $\mathrm{HCl}$ with $150 \mathrm{mM} \mathrm{NaCl}, \mathrm{pH} 8$, and centrifuged for $10 \mathrm{~min}$ at $13,000 \times g, 4{ }^{\circ} \mathrm{C}$. The supernatant was fractionated on a HiPrep Sephacryl S200 High-Resolution column $(16 \times 600$ mm, $47 \mu \mathrm{m}$, GE Healthcare, Uppsala, Sweden). Fractions were eluted through an isocratic gradient with the same buffer at $0.5 \mathrm{~mL} / \mathrm{min}$ flow rate. The fraction that showed the highest PDE activity (S3, $6 \mathrm{mg}$ ) was further fractionated through anion exchange chromatography in a HiTrap ANX (high sub) Sepharose Fast Flow column $(16 \times 25 \mathrm{~mm}$, GE Healthcare, Uppsala, Sweden), previously equilibrated with $50 \mathrm{mM}$ Tris-HCl, $\mathrm{pH}$ 8. Elution was 
performed using a linear gradient $(0-1 \mathrm{M})$ of $\mathrm{NaCl}$ in the same buffer at a flow rate of $5 \mathrm{~mL} / \mathrm{min}$. The fraction that showed the highest PDE activity (A1, $0.7 \mathrm{mg}$ ) was fractionated through cation exchange chromatography in a $10 \times 100 \mathrm{~mm}$ column packed with Carboxymethyl cellulose-52 (CMC-52, GE Healthcare, Uppsala, Sweden). Elution was performed using a segmented gradient from 0 to $100 \%$ of buffer $\mathrm{B}\left(50 \mathrm{mM}\right.$ sodium acetate $\left(\mathrm{CH}_{3} \mathrm{COONa}\right)$ and $\left.1 \mathrm{M} \mathrm{NaCl}, \mathrm{pH} 5\right)$, at $0.5 \mathrm{~mL} / \mathrm{min}$ flow rate. The column was previously equilibrated with buffer $\mathrm{A}(50 \mathrm{mM} \mathrm{CH} \mathrm{COONa} \mathrm{pH} 5)$. In order to evaluate $C d c \mathrm{PDE}$ purity and prepare the sample for structural assays, rerersed-phase chromatography was performed with the fraction that showed the highest PDE activity (C:, $1 \mathrm{mg}$ ) in the cation exchange chromatography. For this purpose, a reversed-phase C4 Jupie, col $\mathrm{mmn}(4.6 \times 250 \mathrm{~mm}, 5 \mu \mathrm{m}, 300 \AA$, Phenomenex, Torrance, CA, USA), previously equilibrat ${ }^{\circ} \mathrm{d} w$ th $0.1 \%$ trifluoroacetic acid (TFA), was used. The elution was performed using a linear g a aent of $0-100 \%$ solution B (80\% acetonitrile $(\mathrm{MeCN})$ in $0.1 \% \mathrm{TFA}$ ) at a $1 \mathrm{~mL} / \mathrm{min}$ flor. at The eluted fraction was collected, frozen, and lyophilized for further analysis. All purificaion steps were performed at Fast Protein Liquid Chromatography Äkta Purifier UPC10 (' jF : Jealthcare, Uppsala, Sweden) and automatically monitored at $280 \mathrm{~nm}$. After each chromatogranı: step, the fractions of interest were concentrated using Amicon ${ }^{\circledR}$ Ultra-15 50K tube (Merck, Sãn Pa، ${ }^{1} \mathrm{O}, \mathrm{SP}$, Brazil) at 4,000 $\times g, 4{ }^{\circ} \mathrm{C}$, for approximately $10 \mathrm{~min}$. The protein amount was estit. ${ }^{7 t} \mathrm{C}^{\mathcal{1}} \mathrm{b}$; determining the sample's absorbance at $280 \mathrm{~nm}$ in a NanoDrop 2000 (Thermo Fisher Scientific inc., Waltham, MA, USA).

\section{2. $C d c$ PDE activity}

$C d c$ PDE activity was determined according to Björk (1963) [43], with modifications proposed by Valério and colleagues (2002) [21], using a 96-well microplate and bis(p-nitrophenyl) phosphate (1 $\mathrm{mM}$ ) as the substrate. Absorbance reading was performed in a microplate reader (Sunrise-basic, Tecan, Männedorf, Switzerland) at $400 \mathrm{~nm}$. Enzyme activity was expressed as the percentage of activity 
relative to the highest absorbance. According to Valério and colleagues (2002) [21], an increase of 1.0 $\mathrm{Abs}_{400 \mathrm{~nm}} / \mathrm{min}$ corresponds to 1 unit of enzymatic activity.

Catalytic activity of $C d c \operatorname{PDE}(0.75 \mu \mathrm{g})$ was evaluated considering three variables: storage temperatures $\left(-80,-20,0,4,25,37,50\right.$, and $70^{\circ} \mathrm{C}$; one hour), $\mathrm{pH}$ values $(7,7.5,8,8.5,9$, and 9.5), and reaction temperatures $\left(0,4,25,37\right.$, and $\left.50^{\circ} \mathrm{C}\right)$. As positive control, PDE was previously incubated with $100 \mathrm{mM}$ Tris- $\mathrm{HCl}, \mathrm{pH}$ 8. Heat inactivated PDE (incubated for $10 \mathrm{~min}$ at $100{ }^{\circ} \mathrm{C}$ ) was used as negative control.

An enzymatic kinetic assay was carried out using different s abs 'rate concentrations (0-5 $\mathrm{mM})$ in order to determine the parameters of the steady-state kinetics for $2 d c$ PDE. Substrate hydrolysis was spectrophotometrically monitored at $400 \mathrm{~nm}, 25^{\circ} \mathrm{C}$, usins th niicroplate reader SpectraMax Plus 384 (Molecular Devices, San Jose, CA, USA). All readors were inade in triplicates, at 3-second intervals for $20 \mathrm{~min}$. The concentration of the product formei was estimated considering its extinction coefficient at $400 \mathrm{~nm}\left(17.6 \mathrm{M}^{-1} \cdot \mathrm{cm}^{-1}\right)$ [17]. The kinetic co. tants $\left(\mathrm{K}_{m}\right.$ and $\left.\mathrm{k}_{\mathrm{cat}}\right)$ were estimated using the equation for Michaelis-Menten kinetics:

$\mathrm{V}_{0}$ : Initial enzyme velority;

$$
V_{0}=\frac{[E] \times k_{c a t} \times[S]}{K_{m}+[S]}
$$

[E]: Enzyme concentro:

[S]: Substrate cor 'en rati on; number);

$\mathrm{k}_{\mathrm{cat}}$ : Number of timc that each enzyme site converts substrate to product per time (turnover

$\mathrm{K}_{m}$ : Michaelis-Menten constant.

For the enzyme inhibition assay, $C d c \mathrm{PDE}$ was incubated for $30 \mathrm{~min}$ at $37{ }^{\circ} \mathrm{C}$ with different concentrations (0.625-10 $\mathrm{mM})$ of the following enzyme inhibitors: $\beta$-mercaptoethanol, cysteine, dithiothreitol (DTT), and ethylenediaminetetraacetic acid (EDTA). All enzymatic assays were performed in triplicates.

All data were processed and analyzed using the GraphPad Prism 8 software (GraphPad Software Inc., La Jolla, CA, USA). 


\subsection{SDS-PAGE and glycosylation}

C. $d$. collilineatus whole venom $(10 \mu \mathrm{g})$ and venom fractions containing $C d c \operatorname{PDE}(5 \mu \mathrm{g})$ were subjected to $10 \%$ SDS-PAGE according to the Laemmli method (1970) [44], under reducing and non-reducing conditions. Low molecular mass (97.0-14.4 kDa, 17-0446-01, GE Healthcare, Uppsala, Sweden) and wide molecular mass (120-10 kDa, M00516s, GenScript, New Jersey, USA) markers were used. The gel was stained with Coomassie ${ }^{\circledR}$ Brilliant Blue G-250 (Sigma-Aldrich, St. Louis, MO, USA).

In order to qualitatively evaluate the glycosylation, $C d c \operatorname{PDE}(30 \mu \mathrm{g}, 12 \mu \mathrm{L})$ was denatured and reduced with 5\% SDS $(1 \mu \mathrm{L})$ and $1 \mathrm{M}$ DTT $(1 \mu \mathrm{L})$, respectively, for $10 \mathrm{mir}$ at $75{ }^{\circ} \mathrm{C}$. After that, $10 \%$ Triton X$100(2 \mu \mathrm{L})$ and $20 \mathrm{U}$ of PNGase F (V4831, Promega, Madison, WI, USA) were added, and the mixture was incubated for three hours at $37^{\circ} \mathrm{C}$. The reaction was stor ted by heating the sample for $10 \mathrm{~min}$ at $100{ }^{\circ} \mathrm{C}$. The sample was analyzed by $10 \%$ SDS-PAC - and ine gel was stained as mentioned above. Reduced $C d c$ PDE without PNGase F was used $\cdots$ a `ontrol.

\subsection{Determining molecular mass and amino a id sequence}

The average molecular mass of $C d \cdot \mathrm{r}$. $\mathrm{E}(10 \mu \mathrm{g})$ was determined by matrix-assisted laser desorption/ionization with a time-c -flight analyzer (MALDI-TOF, RapifleX, Bruker Corporation, Billerica, MA, USA) using FlexCu.trul 4.0 software (Bruker Corporation, Billerica, MA, USA) for data acquisition. The following iara neters were employed in order to obtain data: 10,000 laser shots per spectrum and $500 \mathrm{~Hz}$ laser f equency. The instrument operated in linear positive mode, within a range of 20-220 kDa, and RapifleX was calibrated with bovine serum albumin (BSA, $\sim 66 \mathrm{kDa}[\mathrm{M}+\mathrm{H}]^{+}, \sim 33$ $\mathrm{kDa}[\mathrm{M}+2 \mathrm{H}]^{2+}$, and BSA dimeric form $\left.\sim 132 \mathrm{kDa}[2 \mathrm{M}+\mathrm{H}]^{+}\right)$. As matrix, a saturated solution of sinapinic acid (SA) was prepared in $\mathrm{MeCN}$ and 0.1\% TFA, at the ratio of 3:7. Data analysis was performed using the FlexAnalysis 3.4 software (Bruker Corporation, Billerica, MA, USA).

N-terminal sequencing was performed according to Edman's degradation method (1967) [45], using an automatic protein sequenator (PPSQ-33A, Shimadzu, Kyoto, Japan), following the 


\section{Journal Pre-proof}

manufacturer's instructions. The obtained sequence was compared to databases through the Basic Local Alignment Search Tool (BLAST, https://blast.ncbi.nlm.nih.gov/Blast.cgi) [46], searching for similarity. For bottom-up approach, $C d c \mathrm{PDE}\left(10 \mu \mathrm{g}\right.$ in $12 \mu \mathrm{L}$ of $\left.100 \mathrm{mM} \mathrm{NH}_{4} \mathrm{HCO}_{3}\right)$ was reduced with $10 \mathrm{mM}$ DTT (2 $\mu \mathrm{L}$ of $70 \mathrm{mM} \mathrm{DTT})$ at $56^{\circ} \mathrm{C}, 600 \mathrm{rpm}$, for $40 \mathrm{~min}$, and alkylated with $20 \mathrm{mM}$ iodoacetamide (3 $\mu \mathrm{L}$ of $113.3 \mathrm{mM}$ iodoacetamide) at RT for $30 \mathrm{~min}$, in a dark compartment. Afterward, a second reduction with $11 \mathrm{mM}$ DTT ( $2 \mu \mathrm{L}$ of $104.5 \mathrm{mM}$ DTT, RT, $5 \mathrm{~min}$, dark compartment) was performed. This sample was digested with trypsin $(2 \mu \mathrm{L}$ of $0.1 \mu \mathrm{g} / \mu \mathrm{L}$; ref. 90058 , Thermo Fisher Scientific Inc., Waltham, MA, USA) with a ratio of 1:50 (trypsin: $C d c \mathrm{PDE})$, at $37^{\circ} \mathcal{C}, \varsigma^{-} 0 \mathrm{u} \mathrm{rpm}$, overnight. After that, a second digestion with trypsin was performed with a ratio of 1.100 (trypsin: $C d c$ PDE) and acetonitrile $80 \%(92 \mu \mathrm{L}$ of $100 \% \mathrm{MeCN})$ was added. The sample was $\kappa \mathrm{e}$ a $37^{\circ} \mathrm{C}, 600 \mathrm{rpm}$, for $3 \mathrm{~h}$. The reaction was stopped by adding $10 \%$ v/v TFA $(6 \mu \mathrm{L})$, and tho sampıe was desalted using a reversed-phase ZipTip $^{\circledR}$ C18 column (ref. 87782, Thermo Fis ${ }^{\wedge}$ r i’ientific Inc., Waltham, MA, USA). Peptide mass fingerprint (PMF) of the protein was obtainea 'Ising the same MALDI-TOF equipment mentioned above. RapifleX was however operated in reliectron positive mode and calibrated with a mixture of peptides (Peptide calibration standa: 1, 1000-3200 Da, ref. 206195, Bruker Corporation, Billerica, MA, USA). As matrix, a $10 \mathrm{mg} / \mathrm{\sim}$ L solution of 2,5-dihydroxybenzoic acid (DHB) was prepared in $\mathrm{MeCN}$ and $0.1 \%$ TFA, at a rati of 1:1. Data analysis was performed through FlexAnalysis 3.4 and

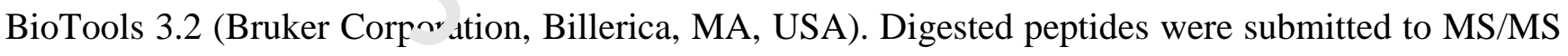
fragmentation through RapifleX, controlled by the software FlexControl 4.0 for data acquisition. MS/MS spectra were interpreted with FlexAnalysis 3.4 and Sequence Editor 3.2 (Bruker Corporation, Billerica, MA, USA).

For LC-MS/MS, three samples of $C d c \mathrm{PDE}(10 \mu \mathrm{g}$ each) were reduced and alkylated as described above. The first one (sample 1) was digested with trypsin, as described above. However, the other two samples (samples 2 and 3) were digested with a mixture of proteases containing trypsin (ref. 90058, Thermo Fisher Scientific Inc., Waltham, MA, USA), chymotrypsin (ref. 90056, Thermo Fisher 
Scientific Inc., Waltham, MA, USA), and endoproteinase Glu-C (ref. 90054, Thermo Fisher Scientific Inc., Waltham, MA, USA) at different ratios (1 U trypsin : $85 \mu \mathrm{g} C d c \mathrm{PDE}, 1 \mathrm{U}$ chymotrypsin : $55 \mu \mathrm{g}$ $C d c \mathrm{PDE}$, and $1 \mathrm{U}$ endoproteinase Glu-C : $85 \mu \mathrm{g} C d c \mathrm{PDE}$ ), at $37^{\circ} \mathrm{C}, 600 \mathrm{rpm}$, for $2 \mathrm{~h}$ [47]. The reaction of samples 1 and 2 was stopped with $0.5 \%$ TFA. For sample 3, the reaction was stopped by an increase in temperature (to $\sim 100^{\circ} \mathrm{C}$ ), for $3 \mathrm{~min}$, and this sample was digested with $\mathrm{N}$-glycosidase $\mathrm{F}$ (ref 11365177001, lot 16070923, Roche, Basel, Switzerland), at the ratio of $5 \mathrm{U}$ N-glycosidase F:100 $\mu \mathrm{g}$ of $C d c$ PDE, $37^{\circ} \mathrm{C}, 600 \mathrm{rpm}$ for $4 \mathrm{~h}$. After these steps, a second digestion with $\mathrm{N}$-glycosidase $\mathrm{F}$ was performed, but with a different glycosidase-to-protein ratio and tir te $1^{3} \mathrm{U}$ N-glycosidase F:100 $\mu \mathrm{g}$ of $C d c \mathrm{PDE}$, overnight) at $37^{\circ} \mathrm{C}, 600 \mathrm{rpm}$. The reaction was stopp $2 \mathrm{~d} v$ ith $0.5 \%$ TFA. Digested materials were analyzed by Acquity UPLC ${ }^{\circledR}$ M-Class (Waters, Mil'orc MA, USA) coupled to a Q-Exactive ${ }^{\mathrm{TM}}$ Plus Hybrid Quadrupole-Orbitrap ${ }^{\mathrm{TM}}$ Mass Spectromet $=$ ( ( Therno Fisher Scientific Inc., Waltham, MA, USA). High-resolution $(70,000 \mathrm{at} \mathrm{m} / z, 200) \mathrm{MS} \sim \eta \mathrm{n} \cdot \mathrm{tra}$ trom trypsin digestion were acquired within the scan range of $400-1750 \mathrm{~m} / z$ and with automat - gain control (AGC) target at $3 \mathrm{e}^{6}$. Subsequently, the twelve most intense ions (+2 or hig'se charge) were fragmented by higher-energy collisional dissociation ( $\mathrm{HCD}$, normalized coll: ion energy of 25), in a data-dependent mode, in which highresolution MS/MS spectra (17,50 at $\mathrm{m} / z$ 200) were acquired within the scan range of $200-2000 \mathrm{~m} / z$ and isolation window of $\pm 2 \mathrm{r} / z$, and with AGC target at $1 \mathrm{e}^{5}$. For those samples with multiple digestions, MS spectra we-e acquired with AGC target at $1 \mathrm{e}^{6}$ within the scan range of 400-1600 m/z, whereas MS/MS spectra were acquired with a normalized collision energy of 28. Other parameters remained the same. All MS/MS spectra were interpreted by automated de novo sequencing, using Peaks Studio 7 software (Bioinformatics Solutions Inc., Waterloo, Canada), against databases extracted by our group, generated from UniProt Knowledgebase (UniProtKB, https://uniprot.org)[48], which comprised protein sequences found in snake venoms (9,421 sequences, keyword "snake"), and PDE sequences from Crotalus venoms (17 sequences, keywords "phosphodiesterase" and "Crotalus") without signal peptide, both downloaded in June 2019. Parent mass and fragment mass error tolerance 
were set to $5 \mathrm{ppm}$ and $0.015 \mathrm{Da}$. Carbamidomethyl cysteine was set as a fixed modification, whereas amidation and methionine oxidation were considered as variable modifications. A maximum of 3 missed cleavages were allowed per peptide.

\section{5. $C d c$ PDE sequence analysis, homology model, and docking simulation}

The primary sequence of $C d c \mathrm{PDE}$ was analyzed for the presence of domains using the conserved domains search tool [49], available at http://www.ncbi.nlm.nih.gov/Structure/cdd/wrpsb.cgi.

A three-dimensional model of $C d c$ PDE was constructed uring the Swiss-Model web server (https://swissmodel.expasy.org/) [50], on automated mode [51]. F،on. ology modeling was performed using the PDE from Taiwan cobra (Naja atra) as a template (P. )B I ): 5GZ4), which was the top hit in the template search (GMQE: 0.94, Sequence identity: $85.0 \%$,

Docking simulation was performed with SwissDock is based on an algorithm that gener ${ }^{+\infty}$ s . nultıple binding modes, estimating their CHARMM force field energies in a grid, evaluating bindiı ${ }_{\varepsilon}$ energies, and selecting the most favorable ones. The

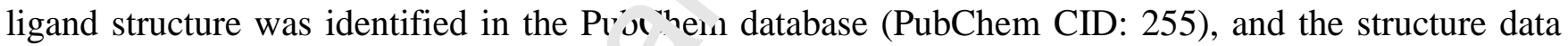
file (SDF) was used along with the cforementioned $C d c$ PDE model in the molecular docking simulations. The model bu ${ }^{1+}$ of $C d c$ PDE was validated using the PROCHECK (https://servicesn.mbi.uclา.e u/P ?OCHECK/)

and

ERRAT (https://servicesn.mbi.ucla. ${ }^{2 d} /$ /ERRAT/) [56] webservers. The final output docked models were visualized and analyzed with the CHIMERA software package (https://cgl.ucsf.edu/chimera/) [57].

\section{6. $C d c P D E$ thermal stability}

Differential scanning fluorimetry (Thermofluor) was used to evaluate $C d c$ PDE thermal stability. The experiment was carried out in a thermocycler Mx3005P (Agilent Technologies, Santa Clara, CA, USA), using SYPRO® orange $(492 / 610 \mathrm{~nm})$ as a fluorescent probe in a 96-well PCR plate. The behavior of $C d c \mathrm{PDE}$ at different $\mathrm{pH}$ and ionic strengths was assayed using Solubility \& Stability Screen 2 (Hampton Research). The $20 \mu \mathrm{L}$ reaction mixture contained $1 \mathrm{mg} / \mathrm{mL}$ of $C d c \mathrm{PDE}$ and $50 \times \mathrm{SYPRO}{ }^{\circledR}$ 
orange. The samples were heated from 25 to $95{ }^{\circ} \mathrm{C}$, at $1{ }^{\circ} \mathrm{C} / \mathrm{min}$ increase rate, and fluorescence was measured every minute. Thermal melting curves were processed according to the protocol described by Niesen and colleagues (2007) [58], and the melting temperature was calculated using GraphPad Prism 8 software.

\subsection{Recognition of crotalid antivenom against $C d c P D E$ and prediction of molecule epitopes}

An ELISA assay was performed using a 96-well microplate (Costar, Corning Incorporated, NY, USA) coated with $C d c \mathrm{PDE}(2 \mu \mathrm{g})$ and $C$. $d$. collilineatus whole venom $(2 \mu \mathrm{g})$ in $0.05 \mathrm{M}$ carbonate/bicarbonate buffer, $\mathrm{pH} 9.6$ (100 $\mu \mathrm{L} /$ well). As positive $\mathrm{c}^{\prime}$ ntı $\mathrm{l}$, some wells were coated with non-immunized horse serum (1:50, H0146, lot SLBS7574, Sign ₹-A drich, St. Louis, MO, USA) in 0.05 M carbonate/bicarbonate buffer, $\mathrm{pH}$ 9.6. The plate was i $\mathrm{cu}_{\iota}$ ated for $16 \mathrm{~h}$ at $4{ }^{\circ} \mathrm{C}$, then was washed three times with phosphate-buffered saline (PBS), $\mathrm{pH}^{7}$ '. Afterward, the plate was blocked by adding $250 \mu \mathrm{L}$ of PBS containing 2\% (w/V) non-fat dr: $\eta_{\mathrm{L}}{ }^{1} \mathrm{k}$ (Molico, Nestlé, Bebey, Switzerland; MPBS) and incubated for $2 \mathrm{~h}$ at $37^{\circ} \mathrm{C}$. The plate was then $\mathrm{w}$ - shed three times with PBS-0.05\% Tween (PBS-T) and three times with PBS and incubated for ${ }^{1} \mathrm{~s}$ at $; 7^{\circ} \mathrm{C}$ with anti-crotalid antivenom (1:100 in 1\% MPBS). As negative control, $C d c \mathrm{PDE}$ and ve: om -oated wells were incubated with non-immunized horse serum diluted 1:100 in 1\% MPBS. The pite was washed three times with PBS-T and PBS, respectively. After that, the plate was incrba ed with $100 \mu \mathrm{L}$ of anti-horse polyclonal antibodies conjugated with peroxidase (IgG-HRP, A6@1- Sigma-Aldrich, St. Louis, MO, USA) diluted 1:3000 in 1\% MPBS. After one hour of incubation at $37^{\circ} \mathrm{C}$, the plate was washed three times with PBS-T and three times with PBS. To each well, $100 \mu \mathrm{L}$ of $o$-phenylenediamine dihydrochloride (OPD)- $\mathrm{H}_{2} \mathrm{O}_{2}$ (SIGMAFAST OPD tablet, SLBM4528V, Sigma-Aldrich, St. Louis, MO, USA), diluted according to the manufacturer's instructions, were added. Finally, the plate was incubated in a dark chamber at RT until color development. Then, the reaction was stopped with $50 \mu \mathrm{L}$ of $1 \mathrm{M} \mathrm{H}_{2} \mathrm{SO}_{4}$ (Merck, São Paulo, SP, Brazil). Absorbance was measure at $490 \mathrm{~nm}$ on a 96-well plate reader (Sunrise-basic Tecan, Männedorf, 
Switzerland). The assay was carried out in quadruplicates, and the results were analyzed by one-way ANOVA, followed by Tukey's post-hoc test $(p<0.05)$.

ABCpred Server, with a threshold of 0.9 and a window length of 14 to 16 residues, was used to predict which $C d c \mathrm{PDE}$ epitopes are recognized by B cells (http://crdd.osdd.net/raghava/abcpred/) [59].

\subsection{Platelet aggregation assay}

Human peripheral blood samples $(\sim 10 \mathrm{~mL})$ were collected with a conventional citrate collection tube (Vacutainer, BD Biosciences, Franklin Lakes, Nova Jersey, US A) from 10 voluntary donors (both genders; 20 to 40 years old; without medical history of taking or 1 a with the blood clotting process) and centrifuged at 1,000 rpr' (1 $2 \mathrm{rcf}$ ), RT, for $10 \mathrm{~min}$, to obtain platelet-rich plasma (PRP). PRP $(450 \mu \mathrm{L})$ was incubated or 5 inin under constant agitation. Different concentrations of $C d c \operatorname{PDE}(15-120 \mu \mathrm{g} / \mathrm{mL})$ and/or $\mathrm{A}^{\mathrm{N}}(2,4 \mu \mathrm{M})$ were added and platelet aggregation was monitored for 6 min using an optical ag ^ey vmeter (Chrono-Log Corporation, Havertown, PA, USA). The assay was performed in triplicates, a. 1 results were analyzed by one-way ANOVA followed by Dunnett's post-hoc test $(p<0.05)$.

This assay was performed fter approval of the research project by Comitê de Ética em Pesquisa (Research Ethics Commı $\left.{ }^{+} e e\right)$, School of Pharmaceutical Sciences of Ribeirão Preto (FCFRPUSP), under the protocol no. 435 - CAAE no. 64850717.8.0000.5403.

\subsection{Cytotoxicity assay in hr.man keratinocytes (N/TERT cells)}

Immortalized human keratinocyte cells $\left(\mathrm{N} / \mathrm{TERT}, 4 \times 10^{3}\right.$ ) were seeded in a 96 -well polystyrene black opaque plate (ref. 237105, Thermo Fisher Scientific, Roskilde, Denmark) and cultured in Dulbecco's modified Eagle's medium (DMEM: F12; Grand Island, NY, USA) with 1\% penicillinstreptomycin and supplemented with $10 \%$ fetal bovine serum (FBS) and 1× RM plus supplement. The plate was incubated at $37^{\circ} \mathrm{C}$, with $5 \% \mathrm{CO}_{2}$ and $85 \%$ humidity overnight. After this period, the medium was aspirated, and fresh medium containing different concentrations of $C d c \mathrm{PDE}(10-200 \mu \mathrm{g} / \mathrm{mL})$ was 
added. The plate was incubated for $24 \mathrm{~h}$ at the same conditions mentioned before. Cell viability was determined with CellTiter-Glo luminescent cell viability assay (Promega, Madison, WI, USA), according to the manufacturer's instructions. The $\mathrm{IC}_{50}$ value was calculated with $\log (C d c \mathrm{PDE})$ versus normalized response and Hill equation, using the GraphPad Prism 8 software (GraphPad Software Inc., La Jolla, CA, USA).

\section{Results}

$C d c \mathrm{PDE}$ was successfully isolated from $C$. $d$. collilineatus verom through the three following chromatographic steps: size exclusion, anion, and cation exchange. $1 \mathrm{th}$ evaluation of $C d c \mathrm{PDE}$ activity, using the specific substrate for PDEs (bis(p-nitrophenyl) phosnl ate) was performed on each fraction of all chromatographic steps to look for the presence of active $\mathcal{C}^{7} \mathrm{t} P \mathrm{PE}$ and select the fraction that would be used in the next steps (Fig. 1A-C). The third chrom -tographıc step (cation exchange) was efficient in the final purification of the enzyme, but it mist have induced some conformational change in the enzyme that caused a reduction in its specific a tivity. Therefore, the fraction A1 (non-pure $C d c \mathrm{PDE}$ obtained after the second chromatograrill slep showing the highest specific activity) may be more suitable than $\mathrm{C} 2$ (pure $C d c \mathrm{PDE}$ obt: 'nea after the third chromatographic step) for applications where the catalytic function is more rele $、 n \iota$ than the purity of the enzyme. Since fraction $\mathrm{C} 2$ corresponds to

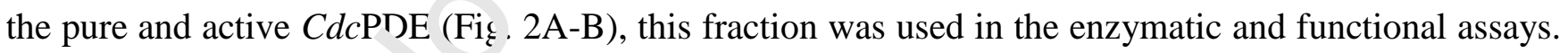
Although PDE activity wa $r$ ot detected after reversed-phase chromatography, this additional step was used to guarantee the $C d c \mathrm{PDE}$ purity (Figure 1D shows the degree of purity for $C d c \mathrm{PDE}$ after the third chromatographic step). This pure fraction (R) was only used in the assays in which the enzymatic activity was not relevant, such as mass spectrometry and other structural characterization assays (e.g. SDS-PAGE). It was also determined that the $C d c \mathrm{PDE}$ enzyme corresponded to $0.71 \%$ of soluble proteins from C. d. collilineatus venom (Table 1).

After each step of $C d c$ PDE isolation, each fraction was analyzed by SDS-PAGE under reducing and non-reducing conditions. From the electrophoretic profiles, it was possible to infer that $C d c \mathrm{PDE}$ 
migrated as a monomer since it presented the expected mass for a classical PDE monomer ( $\sim 90 \mathrm{kDa})$, both in reducing and non-reducing conditions. This assay confirms that the enzyme does not form covalently linked dimers; however, additional studies are needed to determine whether formation of non-covalently linked dimers may occur. In addition, it was possible to observe a difference of $\sim 9 \mathrm{kDa}$ between the reduced $C d c$ PDE and the reduced $C d c$ PDE digested by PNGase (Fig. 2C), evidencing the presence of N-glycosylations in $C d c \mathrm{PDE}$ structure. The entire macromolecule had a mass $[\mathrm{M}+\mathrm{H}]^{+}$of 100,330 and 105,598 Da determined by MALDI-TOF (Fig. 2D). These two masses could correspond to two different $C d c \mathrm{PDE}$ isoforms or glycoforms.

$C d c \mathrm{PDE}$ showed maximal activity between $\mathrm{pH} 8$ and 8.5 on th sut strate bis(p-nitrophenyl) phosphate (Fig. 3A). $\mathrm{pH} 8$ was consequently chosen for the next ex ser nents. $C d c \mathrm{PDE}$ retained its best activity when stored at $0{ }^{\circ} \mathrm{C}$ (Fig. 3B) and the temperature that howed the highest activity was $37^{\circ} \mathrm{C}$ (Fig. $3 \mathrm{C}$ ). For the enzymatic kinetics assays, 15 differer ${ }^{+}$su. strate concentrations were tested, and the product formation curves are shown in Fig. S1. CdcPDe activity follows the Michaelis-Menten model, showing a hyperbolic kinetic curve when $V_{0}$ is plr $\leadsto$ as a function of the substrate concentration (Fig. 3D). The $\mathrm{K}_{m}$ was $0.38 \pm 0.03 \mathrm{mM}$, and $\mathrm{k}_{\text {cat }}$ was $7.14 \pm 2.7 \times 10^{-3} \mathrm{~s}^{-1}$, while its catalytic efficiency $\left(\mathrm{k}_{\text {cat }} / \mathrm{K}_{m}\right)$ was 0.37 $\pm 0.03 \mathrm{mM} \cdot \mathrm{s}^{-1}$. Another assay demı nstrated that the lyophilization process led to a high loss of enzyme activity (data not showr); ' hus. $C d c \mathrm{PDE}$ was not lyophilized prior to enzymatic assays. Regarding inhibitors, $C d c \mathrm{PDE}$ activi, decreased in a dose-dependent manner in all tested concentrations of $\beta$ mercaptoethanol (Fig. 3E), whereas for the other inhibitors (cysteine, DTT, and EDTA) $C d c$ PDE was completely inhibited at all tested concentrations (Table S1). Reference (water) melting temperature $\left(\mathrm{T}_{\mathrm{m}}\right)$ for $C d c$ PDE was $65.71{ }^{\circ} \mathrm{C}$. Melting curves revealed a gain in thermal stability in almost all tested buffers, so that the greatest $\Delta \mathrm{T}_{\mathrm{m}}$ was obtained at $\mathrm{pH} 5.5$ in the absence of salt. In comparison, the protein thermal stability was compromised at $\mathrm{pH} 4.5$ (Fig. 4). 
Following the characterization of $C d c \mathrm{PDE}$ primary structure, the first 26 residues of the N-terminal region were sequenced through Edman degradation. In MS/MS analyzes, when the sample was digested only with trypsin (sample 1), 29,086 spectra generating 1,822 peptides were obtained. However, when the Multi-Enzymatic Limited Digestion (MELD) was performed (sample 2), 82,481 spectra and 8,889 peptides were generated. In addition, digesting the sample with MELD and N-glycosidase F (sample 3) generated 82,955 spectra and 13,062 peptides. All these results together generated a primary sequence of 829 amino acid residues. Finally, the PMF gave a sequence covernge of almost $72 \%$ of the proposed sequence. From these results, we identified 33 conserved cysteine esı'ues and the three potential sites for $\mathrm{N}$-glycosylation conserved in PDEs, except in J3SBP3 (whi $\mathrm{h}$ d es not present the first putative Nglycosylation site). Interestingly, two additional sites to $\mathrm{N}$-glycosylation were also identified. Moreover, the metal ion-binding/active site residues w-me fully conserved. In silico analysis of $C d c \mathrm{PDE}$ primary structure revealed the presence of four don ains: a somatomedin B domain (residues from 11 to 48), a somatomedin B-like domain ( 'sidues from 52 to 95), an ectonucleotide pyrophosphatase/phosphodiesterase dom $\mathbf{1 1}$ - also called autotaxin - (residues from 117 to 483), and a DNA/RNA non-specific domain (res: tues from 581 to 810). Finally, the sequence obtained is similar to other snake venom PDEs, sharing nore than $90 \%$ sequence identity. The determined sequence and its alignment with others PDEs are shown in Fig. 5, while the PMF and the spectra analyzed by de novo sequencing are shown in the : upplementary material (Fig. S2, S3, and S4).

Additionally, with the obtained $C d c$ PDE primary sequence, it was possible to predict/model the secondary and tertiary structures. Molecular modeling suggests that $C d c \mathrm{PDE}$ is composed of $22.7 \% \alpha-$ helices, $16.4 \% \square$-strands, $4 \% 3_{10}$ helices, $20.2 \%$ coils, and $35.2 \%$ turns, besides sixteen disulfide bonds (Fig. 6A-B). The structural model of $C d c \mathrm{PDE}$ is complex, similar to the structures of other members of the alkaline phosphatase-like superfamily (ALP-like superfamily). The GMQE value obtained for this model was 0.94 and QMEAN was determined to -2.64. The PROCHECK analysis showed that $>99 \%$ of the amino acid residues are in the most favored and allowed regions of the corresponding 
Ramachandran plot, and the ERRAT analysis showed an overall quality factor of 87.22 for the $C d c$ PDE model.

Afterwards, docking simulation was used to predict the interaction of $C d c \mathrm{PDE}$ and $\operatorname{bis}(p$ nitrophenyl) phosphate substrate. The simulation demonstrated both the interactions of the residues (D125, T163, H167, D283, H287, D330, and H440) that seem to coordinate with the divalent metal cations (e.g. zinc) in the active site, and the close interaction of T163 residue with the substrate (Fig. 6C-E).

In a different assay, $C d c$ PDE was incubated with the com ale ia crotalid antivenom to assess the antivenom's ability to recognize this protein. The resuls $\mathrm{s}$ lowed that the Brazilian crotalid antivenom was able to efficiently recognize the enzyme (F,g.; 4 ). The result was not surprising since it was predicted in silico that there are 16 epitopes of the enzyme that could be recognized by B cells triggering an antibody response (Fig. 7B).

In functional assays, $C d c \mathrm{PDE}$ inhibited ADP-in ${ }^{1}$ 'lced platelet aggregation in a dose-dependent manner (Fig. 8A and S5). In addition, $C d c \mathrm{PD}^{2}$ howed cytotoxic activity against human keratinocytes in concentrations higher than $10 \mu \mathrm{g} / \mathrm{mL}$ Fig. 8B), presenting an $\mathrm{IC}_{50}$ value of $71.65 \mu \mathrm{g} / \mathrm{mL}$ (Fig. S6).

\section{Discussion}

In Brazil, envenomings caus 'd b Crotalus snakes represented almost $9 \%$ of the total snakebite cases in 2019 [6]. Although it is : 1 Jw percentage, these accidents are responsible for severe envenomings, leading to high fatality rates $[6,60]$. Thus, studying the venoms from Crotalus snakes and their isolated components is of high importance to produce effective antivenoms against them. Since the elucidation of the proteomes and transcriptomes of many snake venoms, studies on nucleases have been prominent because of their presence in numerous snake families [19,38]. However, additional studies regarding their functions during envenoming are needed.

In our study, $C d c \mathrm{PDE}$ isolation was achieved through three chromatographic steps. The first step, i.e. molecular filtration, was crucial for separating $C d c \mathrm{PDE}$ from smaller components, such as 
crotoxin, an enzyme complex constituting $65-68 \%$ of the crotalid venom [61]. In the two additional separation steps (anion exchange followed by cation exchange chromatography), the proteins were purified according to their charge. Basic pIs of PDEs have been previously reported to be between 7.4 and 10.5 [17,20,21,62]. Similarly, in this study, it was seen that at pH 8, CdcPDE did not interact with the cationic resin used in the anion exchange chromatography. Therefore, $C d c$ PDE pI was predicted to be higher than 8 . In the cation exchange chromatography step, which was performed at $\mathrm{pH} 5, \mathrm{CdcPDE}$ seemed to acquire a positive charge, allowing it to interact with the column, and, with the ionic strength increasing ( $\mathrm{NaCl}$ concentration), $C d c \mathrm{PDE}$ was eluted.

After completing the process of $C d c \mathrm{PDE}$ isolation, $\mathrm{u}=\mathrm{v}$ rified that $C d c \mathrm{PDE}$ proportion in soluble venom is in accordance with the PDE yields (les, th 'n 1\%) previously reported for $C$. ruber ruber [20], Trimeresurus mucrosquamatus [63], and $P \sim$ hoia russelli russelli venoms [42].

Our study indicated that $C d c \mathrm{PDE}$ migr ${ }^{+\infty} \mathrm{a}$. 's a monomeric protein, as previously described for PDEs from Agistrodon bilineatus [64] and Both. ops alternatus [21] venoms, named class 1 PDEs [64]. In addition, the N-deglycosylation ass $\_$f foiowed by SDS-PAGE showed that CdcPDE is a Nglycosylated protein, which increase its tıolecular mass by $9 \%$ (considering the determined molecular mass of the primary structure, 94,154 Da). PDEs from C. adamanteus and Vipera lebetina venoms present nine potential $\mathrm{N}^{\mathrm{N}} \mathrm{gl} \cdot{ }^{\prime} \cos$ lation sites $[22,65]$, whereas no carbohydrates were reported to be linked to the other snake $v^{\sim n}$ sm PDEs $[63,66]$. This post-translational modification may be involved in the stability of the molecule. In addition, glycosylation may have an effect on inflammatory reactions and cellular signaling $[67,68]$, as well as it may contribute to snake venom diversity through changing toxin conformation and, consequently, its function [69-72].

$C d c$ PDE molecular masses are quite similar to other monomeric PDEs, such as those reported from Cerastes cerastes (110 kDa) [66] and B. alternatus (105 kDa) venoms [21]. However, in these two cases, PDE molecular masses were estimated by SDS-PAGE while the methodology used in our study is more accurate. There are possibly two isoforms or glycoforms of $C d c \mathrm{PDE}$ in the venom, since there 
were two molecular masses determined; and it is known that snake venom may contain more than one PDE isoform [73]. Thus, it is possible that $C d c \mathrm{PDE}$ molecules with different glycosylation patterns or partially cleaved by proteases are present in the venom.

Regarding $C d c$ PDE enzyme activity, it is known that exonucleases have greater activity at basic $\mathrm{pH}[10]$. Our results corroborate with this finding. However, different PDEs may show maximal activity at different basic $\mathrm{pH}$, e.g. PDEs from B. alternatus ( $\mathrm{pH}$ ranging from 7.5 to 9.5) [21], V. lebetina ( $\mathrm{pH}$ 8.8) [22], and A. bilineatus (pH ranging from 9 to 11) [64].

Previous studies show that the optimum temperature for $\mathrm{P} J \mathrm{E}$. varies between $55-60{ }^{\circ} \mathrm{C}$, with loss of activity occurring at temperatures between $65-70^{\circ}$ (' $\left.[2), 21,43,62,63,66,74\right]$, but $C d c P D E$ showed its maximum activity at $37{ }^{\circ} \mathrm{C}$. This difference $\iota$ uid be correlated to the experimental conditions, such as $\mathrm{pH}$ and salinity of the buffer, $\cdots \mathrm{u}$ to ineasure the PDE activity. Also, in our experimental setup, the highest temperature errluc ${ }^{+}$ed was $50{ }^{\circ} \mathrm{C}$, which presented $\sim 72 \%$ of the PDE activity, indicating the initial decay of enzyme a tivity. Furthermore, the Thermofluor analysis suggests that the loss of enzyme activity reporter $\mathrm{I},+\mathrm{DEs}$ at temperatures above $65{ }^{\circ} \mathrm{C}$ may be related to the unfolding caused by an increase in te: pper uture.

In addition, we observed th. ${ }^{t}$ water loss during vacuum centrifugation or lyophilization can lead to more than $30 \%$ and $90 \%$ red iction in enzyme activity, respectively. This observation corroborates with the findings of Björk (1963) that evidenced a reduction of more than $25 \%$ in PDE activity after lyophilization [43].

Regarding kinetic parameters, although the $C d c \mathrm{PDE} \mathrm{K}_{m}(0.38 \mathrm{mM})$ is lower than those described for PDEs obtained from other snakes, such as B. jararaca $(21.88 \mathrm{mM})$ [41], B. alternatus (2.69 $\mathrm{mM})$ [21], and $C$ cerastes $(4.33 \mathrm{mM})$ [66], it is very close to the $\mathrm{K}_{m}$ value of D. russelli PDE (0.308 $\mathrm{mM})$ [42]. The low $\mathrm{K}_{\mathrm{m}}$ value of the D.russelli PDE and CdcPDE show that these enzymes have 7 to 57 times more affinity for the used substrate compared to the aforementioned PDEs. On the other hand, $C d c \mathrm{PDE} \mathrm{k}_{\mathrm{cat}}\left(0.14 \mathrm{~s}^{-1}\right)$ is higher than that observed for the B. jararaca PDE $\left(4.4 \times 10^{-4} \mathrm{~s}^{-1}\right)$ [41]; 


\section{Journal Pre-proof}

while catalytic efficiency was determined to $0.37 \mathrm{mM} . \mathrm{s}^{-1}$ for $C d c \mathrm{PDE}$ and $2 \times 10^{-5} \mathrm{mM} . \mathrm{s}^{-1}$ for the $B$. jararaca PDE, indicating a greater kinetic effectiveness of $C d c$ PDE. However, since the reaction buffer $\mathrm{pH}$ is not similar, the differences observed in the catalytic constants could be related to the different physico-chemical environment.

Inhibition of $C d c \mathrm{PDE}$ by $\beta$-mercaptoethanol in a dose-dependent manner has also been observed in other PDEs, such as those from B. alternatus [21] and C. cerastes [66]. Total CdcPDE inhibition caused by other reducing agents, such as DTT and cysteine, sug ests that disulfide bonds may be essential for the enzymatic activity, as it has been described for the गD上 from N. nigricollis venom [75]. In our study, $C d c$ PDE, similarly to many other PDEs $[18,66,74]$, wa, inhibited by EDTA. Knowing that EDTA is a metal chelating agent, our result indicates that $C d c$ ' DE is a metalloenzyme similar to many other PDEs, including PDE from $C$. adamanteus ven su that presents zinc, magnesium, and calcium in its structure [15], PDE from Trimeresurus $\iota^{:} \iota_{\delta}^{\circ}$ ori venom that presents zinc and copper in its structure [26], and PDE from D. russelli venom t. at presents only zinc in its structure [42].

$C d c$ PDE primary structure was $1 \mathrm{e}^{1} \mathrm{c}$-mined through a combination of Edman degradation and mass spectrometry, using tryptic diģ tion and MELD. The use of MELD method is known to present some advantages, including the higi number and diversity of the obtained peptides. In addition, MELD gives a higher percentare of protein coverage, facilitating the sequencing [47]. Combining the sequencing methods applic:, it was observed that $C d c$ PDE shares a high sequence identity with other snake PDEs, as described above. It was also noted that $C d c$ PDE has two sites for N-glycosylation (NFS and NGS, at positions 194-196 and 237-239, respectively) alongside three more potential sites (NET, NLT, and NHS, at positions 17-19, 383-385 and 572-574 respectively). This suggest that the same PDE isoform with differences in their glycosylation pattern (i.e. either in quantity or in type of glycosylation) may be present in the venom. Our results corroborate with findings reported for PDEs from $V$. lebetina 
and $C$. adamanteus venoms, in which 33 cysteines and 9 putative $\mathrm{N}$-glycosylations sites were observed $[22,65]$.

As mentioned earlier, PDEs can be present in snake venoms in different forms. In this study, based on the SDS-PAGE results and the template (5GZ4), we modeled the $C d c \mathrm{PDE}$ in a monomeric form. A monomeric model of PDB previously built by Ullah and colleagues (2019) displays the same number of disulfide bonds as our $C d c$ PDE model (16 disulfide bonds) [65]. Moreover, both models show a divalent metal cation in the active site of the enzyme that is in accordance with other snake and human PDE findings $[15,20,65,76]$. Therefore, possessing the cor ser va metal ion-binding/active site residues and being inhibited by EDTA, $C d c$ PDE was determir ed t ) be a metalloenzyme. In addition, substrate binding was predicted to occur in the active sıte, directly interacting with T163, and the substrate positioning seems to agree with observation of how AMP is bound to the PDE from Taiwan cobra (Naja atra) (PDB ID: 5GZ5). Further $\cdots \eta$ 'rt can be found from previous reports, where the T163 residue was demonstrated to be importanı for the enzymatic activity of other snake venom PDEs $[22,65]$.

Currently, the only available treaıment for snakebite envenoming is administration of animal plasma-derived antivenom $\left[77,78_{\lrcorner}\right.$, and it is possibly medically important that anti-crotalid antivenom recognizes $C d c$ PDE. Our res lilts lemonstrate that the tested Brazilian antivenom specifically recognizes both venom and PDE from $C$. $d$. collilineatus. Despite being present in small proportions in snake venoms [38], it is not surprising that crotalid antivenoms comprises specific antibodies targeting $C d c \mathrm{PDE}$, since it is a high molecular weight protein with likely high immunogenicity. Some authors suggest that the ideal size for epitopes that have immunogenicity is greater than 10 and not more than 20 residues $[79,80]$. Indeed, our epitope prediction revealed that the enzyme presents sixteen epitopes of such lengths that could possibly be recognized by the immune system.

The functional activities induced by the $C d c$ PDE were also explored in this study. Known as inhibitors of platelet aggregation, PDEs can hydrolyze ADP, an agonist that leads to aggregation [10]. 
Our results demonstrated that $C d c \mathrm{PDE}$ reduces ADP-induced platelet aggregation as it was previously demonstrated for PDEs from venoms of B. jararaca, D. russelli, and T. stejnegeri [26,41,42]. Physiologically, injuries occurring in blood vessels lead to ADP-induced platelet aggregation, forming a blood clot. However, when this activation is not controlled, thrombus formation can occur, which causes further damage to the body $[81,82]$. Thus, $C d c$ PDE could be a promising molecule to study thrombosis. It may even find a potential therapeutic application similar to Tirofiban (Aggrastat ${ }^{\circledR}$ ) and Eptifibatide $\left(\right.$ Integrilin ${ }^{\circledR}$ ) that are snake-derived drugs capable $r f$ inhibiting platelet aggregation approved by the US Food and Drug Administration (FDA) $[83,84]$.

This study also demonstrated that $C d c \mathrm{PDE}$ has a cvi tox $\mathrm{c}$ effect on human keratinocytes. $C d c$ PDE decreased the viability of N/TERT cells with an $I_{-50}$ tt $71.65 \mu \mathrm{g} / \mathrm{mL}$. Different cellular assays have been developed to evaluate the cytotoxicity of sxins $m$ vitro [85-88], however, there are few studies using human keratinocytes to assess $-t^{+}$'xicity of snake toxins $[89,90]$, being our study pioneer to demonstrate that a PDE from snake , noms is cytotoxic to human keratinocytes. Since skin cells are usually affected in snakebite en,$e$. nnings [91,92], it is relevant to evaluate the effect of snake toxins in keratinocytes. Although the 'ocai effects of crotalid envenoming are less evident than systemic effects [93], additional studies re needed to understand the local effects of crotalid toxins. Unfortunately, functiona $C_{c} \subseteq$ PL E studies could not be expanded due to the low yield of the enzyme.

\section{Conclusion}

Here, we report the isolation and characterization of a novel snake PDE from C. d. collilineatus venom, i.e. $C d c$ PDE. Only few studies on snake PDEs are available in the literature, and our study thus contributes to expanding the knowledge on this enzymatic toxin class by providing data on protein structure, enzymatic activity, thermostability, and cytotoxicity, as well as a structural protein-substrate interaction model. This study highlights cytotoxicity properties of $C d c$ PDE on human keratinocytes, which could be further explored to strengthen our knowledge on local effects of rattlesnake envenomings. Finally, PDEs could become important research or therapeutic tools, since they present 
several biochemical functions that could be exploited to manipulate physiological and pathological processes, such as platelet aggregation.

\section{Funding}

This study was supported by Fundação de Amparo à Pesquisa do Estado de São Paulo (FAPESP, São Paulo Research Foundation, scholarships to ISO 2017/03580-9 and 2018/21233-7, GAW 2017/00586-6 and grants 2011/23236-4 and 2019/10173-6), Coordenação de Aperfeiçoamento de Pessoal de Nível Superior (CAPES, Coordination for the Improvement of Higher Education Personnel, Finance Code 001), Conselho Nacional de Desenve vur onto Científico e Tecnológico (CNPq, The National Council for Scientific and Technologic al I evelopment, scholarship to MBP 307155/2017-0 and grant 306479/2017-6), and the Villu $n$ Foundation (grant 00025302). UK acknowledges support by a Novo Nordisk rouncation Young Investigator Award (NNF16OC0020670). Mass spectrometers used $f_{\text {O1 }}$ this project were supported by the Walloon Region (Belgium) and the European Regional Developn``nt Fund (ERDF).

\section{CRediT author statement}

ISO was responsible for project dev lopıent, designed the experimental approaches, interpreted the data, and wrote the manuscript. $\mathrm{G}_{i} \mathrm{~W}, \mathrm{IAC}, \mathrm{KCFB}, \mathrm{KK}, \mathrm{SA}$, and $\mathrm{MCN}$ contributed in purification and characterization assays. MB $>$, N AS, SVS, AHL, and UK contributed with the functional assays. DB and LQ contributed with nass spectrometry analysis. ECA coordinated and designed all the experiments, analyzed and interpreted the data. All authors read, corrected, and approved the final manuscript.

\section{Competing interests}

The authors declare that they have no competing interests.

\section{References}

[1] J.J. Calvete, Y. Rodríguez, S. Quesada-Bernat, D. Pla, Toxin-resolved antivenomics-guided assessment of the immunorecognition landscape of antivenoms, Toxicon. 148 (2018) 107-122. 
https://doi.org/10.1016/j.toxicon.2018.04.015.

[2] J.M. Gutiérrez, J.A. Pereañez, The need for an integrated approach in confronting snakebite envenoming in latin america: the relevance of endogenous scientific and technoogical research, Vitae. 23 (2016) 103-105. https://doi.org/10.17533/udea.vitae.v23n2a01.

[3] L.S. Cruz, R. Vargas, A.A. Lopes, Snakebite envenomation and death in the developing world, Ethn Dis. 19 (2009) S1-42-6.

[4] World Health Organization, ed., Rabies and envenomings: a reglected public health issue ; report of a consultative meeting, World Health Organization, Gener d, ı ? sanuary 2007, WHO, Geneva, 2007.

[5] F.M.O. Pinho, I.D. Pereira, Ofidismo, Rev. Assoc. 'vei bras. 47 (2001) 24-29. https://doi.org/10.1590/S0104-42302001000100026.

[6] Ministério da Saúde, Acidentes por anim -is ^eçonhentos - Notificações registradas no Sistema de Informação de Agravos de Notificação - Bras.' (2020).

http://tabnet.datasus.gov.br/cgi/deftohtm ¿x:?sinannet/cnv/animaisbr.def (accessed August 16, 2020).

[7] H.C. Costa, R.S. Bérnils, Rér ‘is cio Brasil e suas Unidades Federativas: Lista de espécies, Herpetologia Brasileira. 7 (2018).

[8] J.J. Calvete, Venrmi s: il tegrative venom proteomics and beyond, Biochem. J. 474 (2017) 611-634. https://doi.org/1C 1'J42/BCJ20160577.

[9] J.J. Calvete, P. Juárez, L. Sanz, Snake venomics. Strategy and applications, J Mass Spectrom. 42 (2007) 1405-1414. https://doi.org/10.1002/jms.1242.

[10] B.L. Dhananjaya, C.J.M. D Souza, An overview on nucleases (DNase, RNase, and phosphodiesterase) in snake venoms, Biochemistry Mosc. 75 (2010) 1-6. https://doi.org/10.1134/s0006297910010013.

[11] C. Delezenne, H. Morel, Action catalytique des venins des serpents sur les acids nucleiques, CR Acad. Sci. (1919) 244-246. 
[12] A.R. Taborda, L.C. Taborda, J.N. Williams, C.A. Elvehjem, A study of the desoxyribonuclease activity of snake venoms, J. Biol. Chem. 195 (1952) 207-213.

[13] A.R. Taborda, L.C. Taborda, J.N. Williams, C.A. Elvehjem, A study of the ribonuclease activity of snake venoms, J. Biol. Chem. 194 (1952) 227-233.

[14] S. Uzawa, Über Die phosphomonoesterase und die phosphodiesterase, The Journal of Biochemistry. 15 (1932) 19-28.

[15] L.B. Dolapchiev, R.A. Vassileva, K.S. Koumanov, Venom ex onuclease. II. Amino acid composition and carbohydrate, metal ion and lipid content in the $\mathrm{Cr}$ stai $\bullet$ s adamanteus venom exonuclease, Biochim. Biophys. Acta. 622 (1980) 331-336. http s://a ji.org/10.1016/00052795(80)90044-6.

[16] R.M. Kini, T.V. Gowda, Rapid method for sep - anton and purification of four isoenzymes of phosphodiesterase from Trimeresurus flavovirir: (i abu snake) venom, Journal of Chromatography A. 291 (1984) 299-305. https://doi.org/10.1016/Sい`'1-9673(00)95032-5.

[17] S.S.M. Al-Saleh, S. Khan, Purifir al $\wedge n$ and characterization of phosphodiesterase I from Walterinnesia aegyptia venom, Prep. Bioc'iem. Biotechnol. 41 (2011) 262-77. https://doi.org/10.1080/10826068.¿n1 i.575319.

[18] S. Perron, S.P. Mack 'ssy. R.M. Hyslop, Purification and characterization of exonuclease from rattlesnake venom, J. Colo v yo. Acad. Sci. 25 (1993) 21-22.

[19] J.W. Fox, A brief review of the scientific history of several lesser-known snake venom proteins: 1-amino acid oxidases, hyaluronidases and phosphodiesterases, Toxicon. 62 (2013) 75-82. https://doi.org/10.1016/j.toxicon.2012.09.009.

[20] N. Mori, T. Nikai, H. Sugihara, Phosphodiesterase from the venom of Crotalus ruber ruber, Int. J. Biochem. 19 (1987) 115-119. https://doi.org/10.1016/0020-711x(87)90321-1.

[21] A.A. Valério, A.C. Corradini, P.C. Panunto, S.M. Mello, S. Hyslop, Purification and characterization of a phosphodiesterase from Bothrops alternatus snake venom, J. Protein Chem. 21 
(2002) 495-503. https://doi.org/10.1023/a:1022414503995.

[22] K. Trummal, A. Aaspõllu, K. Tõnismägi, M. Samel, J. Subbi, J. Siigur, E. Siigur,

Phosphodiesterase from Vipera lebetina venom - structure and characterization, Biochimie. 106 (2014) 48-55. https://doi.org/10.1016/j.biochi.2014.07.020.

[23] M. Segovia, F.L. Figueroa, Detection of a 3', 5'-cyclic-AMP phosphodiesterase activity in the lichenized fungus Evernia prunastri, Plant Biosystems - An International Journal Dealing with All Aspects of Plant Biology. 141 (2007) 123-127. https://doi.org/10.1089/11263500601153610.

[24] M.J. Perry, G.A. Higgs, Chemotherapeutic potential of phos snc tiesterase inhibitors, Curr Opin Chem Biol. 2 (1998) 472-481. https://doi.org/10.1016/s1367-59 31(५3)80123-3.

[25] Y.H. Jeon, Y.-S. Heo, C.M. Kim, Y.-L. Hyun, T.G. Le s. Ro, J.M. Cho, Phosphodiesterase: overview of protein structures, potential therapeutic ar-1ications and recent progress in drug

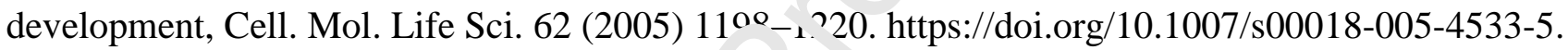
[26] L. Peng, X. Xu, D. Shen, Y. Zhang, J. Sc.'g, X. Yan, M. Guo, Purification and partial characterization of a novel phosphodiest $\ddot{a}$. platelet aggregation, Biochimie. 93 (2)11, 1601-1609. https://doi.org/10.1016/j.biochi.2011.05.027. [27] S. Pérez-Torres, R. Cortés, М. Tolnay, A. Probst, J.M. Palacios, G. Mengod, Alterations on phosphodiesterase type 7 an 8 i: ozyme mRNA expression in Alzheimer's disease brains examined by in situ hybridization, Exp. Nf arol. 182 (2003) 322-334. https://doi.org/10.1016/s0014-4886(03)000426.

[28] A. Castro, M.J. Jerez, C. Gil, A. Martinez, Cyclic nucleotide phosphodiesterases and their role in immunomodulatory responses: advances in the development of specific phosphodiesterase inhibitors, Med Res Rev. 25 (2005) 229-244. https://doi.org/10.1002/med.20020.

[29] C.L. Miller, C. Yan, Targeting cyclic nucleotide phosphodiesterase in the heart: therapeutic implications, J Cardiovasc Transl Res. 3 (2010) 507-515. https://doi.org/10.1007/s12265-010-9203-9. 
phosphodiesterase (PDE) isoenzymes as pharmacologic targets in urology: present and future, Eur. Urol. 50 (2006) 1194-1207; discussion 1207. https://doi.org/10.1016/j.eururo.2006.05.025.

[31] C. Mehats, C.B. Andersen, M. Filopanti, S.-L.C. Jin, M. Conti, Cyclic nucleotide phosphodiesterases and their role in endocrine cell signaling, Trends in Endocrinology \& Metabolism. 13 (2002) 29-35. https://doi.org/10.1016/S1043-2760(01)00523-9.

[32] M. Massimi, S. Cardarelli, F. Galli, M.F. Giardi, F. Ragusa, N. Panera, B. Cinque, M.G. Cifone, S. Biagioni, M. Giorgi, Increase of Intracellular Cyclic AMP by PDE^ Inhibitors Affects HepG2 Cell Cycle Progression and Survival, Journal of Cellular Biochemistry. 1 18 (2017) 1401-1411. https://doi.org/10.1002/jcb.25798.

[33] I.S. de Oliveira, I.A. Cardoso, K. de C.F. Bordon, S.E.1 Carone, J. Boldrini-França, M.B. Pucca, K.F. Zoccal, L.H. Faccioli, S.V. Sampaio, J.C. n nsa, E.C. Arantes, Global proteomic and functional analysis of Crotalus durissus collilin $\sim$ tu individual venom variation and its impact on envenoming, J Proteomics. 191 (2019) 153-165. https://doi.org/10.1016/j.jprot.2018.02.020.

[34] F.G. Amorim, R. Morandi-Filho, i... r ujimura, C. Ueira-Vieira, S.V. Sampaio, New findings from the first transcriptome of the Bc hrops moojeni snake venom gland, Toxicon. 140 (2017) 105117. https://doi.org/10.1016/j.toxic ^n.2017.10.025.

[35] E.L.H. Tang, C.H T. n, S Y. Fung, N.H. Tan, Venomics of Calloselasma rhodostoma, the Malayan pit viper: a complax toxin arsenal unraveled, J Proteomics. 148 (2016) 44-56. https://doi.org/10.1016/j.jprot.2016.07.006. [36] Z.-M. Yang, Y.-E. Yang, Y. Chen, J. Cao, C. Zhang, L.-L. Liu, Z.-Z. Wang, X.-M. Wang, Y.M. Wang, I.-H. Tsai, Transcriptome and proteome of the highly neurotoxic venom of Gloydius intermedius, Toxicon. 107 (2015) 175-186. https://doi.org/10.1016/j.toxicon.2015.08.010. [37] F.G. Amorim, T.R. Costa, D. Baiwir, E. De Pauw, L. Quinton, S.V. Sampaio, Proteopeptidomic, functional and immunoreactivity characterization of Bothrops moojeni snake venom: influence of snake gender on venom composition, Toxins (Basel). 10 (2018). 
https://doi.org/10.3390/toxins10050177.

[38] J. Boldrini-França, C.T. Cologna, M.B. Pucca, K. de C.F. Bordon, F.G. Amorim, F.A.P. Anjolette, F.A. Cordeiro, G.A. Wiezel, F.A. Cerni, E.L. Pinheiro-Junior, P.Y.T. Shibao, I.G. Ferreira, I.S. de Oliveira, I.A. Cardoso, E.C. Arantes, Minor snake venom proteins: Structure, function and potential applications, Biochim Biophys Acta Gen Subj. 1861 (2017) 824-838. https://doi.org/10.1016/j.bbagen.2016.12.022.

[39] F.E. Russell, F.W. Buess, M.Y. Woo, Zootoxicological properties of venom phosphodiesterase, Toxicon. 1 (1963) 99-108. https://doi.org/10.1016/0041-0101(63)9r,טハ-У.

[40] S.D. Aird, Ophidian envenomation strategies and the rol of urines, Toxicon. 40 (2002) 335393. https://doi.org/10.1016/s0041-0101(01)00232-x.

[41] M.L. Santoro, T.S. Vaquero, A.F. Paes Leme, N N.T. Strrano, NPP-BJ, a nucleotide pyrophosphatase/phosphodiesterase from Bothr? ns, iraraca snake venom, inhibits platelet aggregation, Toxicon. 54 (2009) 499-512. https..'/doi.org/10.1016/j.toxicon.2009.05.016.

[42] J. Mitra, D. Bhattacharyya, Phosr il tiesterase from Daboia russelli russelli venom: purification, partial characterization a nd 1h hibition of platelet aggregation, Toxicon. 88 (2014) 1-10. https://doi.org/10.1016/j.toxicon.2̌14.06.004.

[43] W. Björk, Purificatic 1 of thosphodiesterase from Bothrops atrox venom, with special consideration of the elimin ti $^{\text {jn }}$ of monophosphatases, J. Biol. Chem. 238 (1963) 2487-2490.

[44] U.K. Laemmli, Cleavage of structural proteins during the assembly of the head of bacteriophage T4, Nature. 227 (1970) 680-685. https://doi.org/10.1038/227680a0.

[45] P. Edman, G. Begg, A Protein Sequenator, Eur J Biochem. 1 (1967) 80-91. https://doi.org/10.1111/j.1432-1033.1967.tb00047.x.

[46] S.F. Altschul, T.L. Madden, A.A. Schäffer, J. Zhang, Z. Zhang, W. Miller, D.J. Lipman, Gapped BLAST and PSI-BLAST: a new generation of protein database search programs, Nucleic Acids Res. 25 (1997) 3389-3402. https://doi.org/10.1093/nar/25.17.3389. 
D. Morsa, D. Baiwir, R. La Rocca, T.A. Zimmerman, E. Hanozin, E. Grifnée, R. Longuespée,

M.-A. Meuwis, N. Smargiasso, E.D. Pauw, G. Mazzucchelli, Multi-Enzymatic Limited Digestion: The Next-Generation Sequencing for Proteomics?, J. Proteome Res. 18 (2019) 2501-2513.

https://doi.org/10.1021/acs.jproteome.9b00044.

[48] The UniProt Consortium, UniProt: a worldwide hub of protein knowledge, Nucleic Acids Research. 47 (2019) D506-D515. https://doi.org/10.1093/nar/gky1049.

[49] A. Marchler-Bauer, M.K. Derbyshire, N.R. Gonzales, S. Lu, F. Chitsaz, L.Y. Geer, R.C. Geer, J. He, M. Gwadz, D.I. Hurwitz, C.J. Lanczycki, F. Lu, G.H. Marchl rr, ; S. Song, N. Thanki, Z. Wang, R.A. Yamashita, D. Zhang, C. Zheng, S.H. Bryant, CDD: NCBI s cc aserved domain database, Nucleic Acids Research. 43 (2015) D222-D226. https://doi.org/10. US?/rıar/gku1221.

[50] T. Schwede, J. Kopp, N. Guex, M.C. Peitsch, srroisS-MiODEL: An automated protein homology-modeling server, Nucleic Acids Res 21, ?003) 3381-3385. https://doi.org/10.1093/nar/gkg520.

[51] A. Waterhouse, M. Bertoni, S. Bi -n . rt, G. Studer, G. Tauriello, R. Gumienny, F.T. Heer, T.A.P. de Beer, C. Rempfer, L. Bordoli, R. I poı z, T. Schwede, SWISS-MODEL: homology modelling of protein structures and complexes, I'Icieic Acids Res. 46 (2018) W296-W303. https://doi.org/10.1093/nar/g ky4. 7.

[52] A. Grosdidier, V. Zne .e, O. Michielin, SwissDock, a protein-small molecule docking web service based on EADock DSS, Nucleic Acids Res. 39 (2011) W270-277. https://doi.org/10.1093/nar/gkr366.

[53] A. Grosdidier, V. Zoete, O. Michielin, Fast docking using the CHARMM force field with EADock DSS, J Comput Chem. 32 (2011) 2149-2159. https://doi.org/10.1002/jcc.21797. [54] RomanA. Laskowski, J.AntoonC. Rullmann, MalcolmW. MacArthur, R. Kaptein, JanetM. Thornton, AQUA and PROCHECK-NMR: Programs for checking the quality of protein structures solved by NMR, J Biomol NMR. 8 (1996). https://doi.org/10.1007/BF00228148. 
[55] R.A. Laskowski, M.W. MacArthur, D.S. Moss, J.M. Thornton, PROCHECK: a program to check the stereochemical quality of protein structures, J Appl Crystallogr. 26 (1993) 283-291. https://doi.org/10.1107/S0021889892009944.

[56] C. Colovos, T.O. Yeates, Verification of protein structures: Patterns of nonbonded atomic interactions, Protein Sci. 2 (1993) 1511-1519. https://doi.org/10.1002/pro.5560020916.

[57] E.F. Pettersen, T.D. Goddard, C.C. Huang, G.S. Couch, D.M. Greenblatt, E.C. Meng, T.E. Ferrin, UCSF Chimera--a visualization system for exploratory researrh and analysis, J Comput Chem. 25 (2004) 1605-1612. https://doi.org/10.1002/jcc.20084.

[58] F.H. Niesen, H. Berglund, M. Vedadi, The use of differe tial scanning fluorimetry to detect ligand interactions that promote protein stability, Nature Pr Jto ols. 2 (2007) 2212-2221. https://doi.org/10.1038/nprot.2007.321.

[59] S. Saha, G.P.S. Raghava, Prediction of $\cdots \eta$ l. $^{-}$uous B-cell epitopes in an antigen using recurrent neural network, Proteins. 65 (2006) 40-48. https. "/doi.org/10.1002/prot.21078.

[60] J.M. Medeiros, I.S. Oliveira, I.G. rt reıa, G.M. Alexandre-Silva, F.A. Cerni, U. Zottich, M. B. Pucca, Fatal Rattlesnake Envenomat: $\cdot n$ in Northernmost Brazilian Amazon: A Case Report and Literature Overview, Reports. 3 ('乞つ) 9. https://doi.org/10.3390/reports3020009.

[61] M.H. da Silva, O G. 3ier. Titration of antiserum to South American rattlesnake (Crotalus durissus terrificus) venom hr inhibition of phospholipase A2 activity, Toxicon. 20 (1982) 563-569. https://doi.org/10.1016/0041-0101(82)90050-2.

[62] G.R. Philipps, Purification and characterization of phosphodiesterase from Crotalus venom, Hoppe-Seyler’s Z. Physiol. Chem. 356 (1975) 1085-1096. https://doi.org/10.1515/bchm2.1975.356.2.1085.

[63] H. Sugihara, T. Nikai, M. Naruse, M. Kishida, N. Mori, Purification and characterization of phosphodiesterase from the venom of Trimeresurus mucrosquamatus, Int. J. Biochem. 18 (1986) 203207. https://doi.org/10.1016/0020-711x(86)90106-0. 
[64] S.S.M. Al-Saleh, S.U. Khan, M. Ashraf, Biochemical characterization and some biological properties of the phosphodiesterase I purified from Agistrodon bilineatus venom, Indian J Biochem Biophys. 46 (2009) 221-229.

[65] A. Ullah, K. Ullah, H. Ali, C. Betzel, S. ur Rehman, The Sequence and a Three-Dimensional Structural Analysis Reveal Substrate Specificity among Snake Venom Phosphodiesterases, Toxins. 11 (2019) 625. https://doi.org/10.3390/toxins 11110625.

[66] H.Y. Halim, E.A. Shaban, M.M. Hagag, E.W. Daoud, M.F. el Asmar, Purification and characterization of phosphodiesterase (exonuclease) from Cerastes eru stes (Egyptian sand viper) venom, Toxicon. 25 (1987) 1199-1207. https://doi.org/10.1016/ 104 j-0101(87)90138-3.

[67] K.W. Moremen, M. Tiemeyer, A.V. Nairn, Vertebr ^te ${ }_{1}$ rotein glycosylation: diversity, synthesis and function, Nat. Rev. Mol. Cell Biol. 13 (2n1'z) 44〉-462. https://doi.org/10.1038/nrm3383. [68] S.R. Stowell, T. Ju, R.D. Cummings, $\operatorname{Pr}^{n+e} \mathbf{1}_{1}$. glycosylation in cancer, Annu Rev Pathol. 10 (2015) 473-510. https://doi.org/10.1146/annurev nathol-012414-040438.

[69] R. Doley, R.M. Kini, Protein com pı. xes in snake venom, Cell. Mol. Life Sci. 66 (2009) 28512871. https://doi.org/10.1007/s00018 709-3050-2.

[70] N.R. Casewell, S.C. Wagsı ff, W. Wüster, D.A.N. Cook, F.M.S. Bolton, S.I. King, D. Pla, L. Sanz, J.J. Calvete, R.A. Harı son Medically important differences in snake venom composition are dictated by distinct postger r. .ic mechanisms, Proc. Natl. Acad. Sci. U.S.A. 111 (2014) 9205-9210. https://doi.org/10.1073/pnas.1405484111.

[71] D. Andrade-Silva, A. Zelanis, E.S. Kitano, I.L.M. Junqueira-de-Azevedo, M.S. Reis, A.S. Lopes, S.M.T. Serrano, Proteomic and Glycoproteomic Profilings Reveal That Post-translational Modifications of Toxins Contribute to Venom Phenotype in Snakes, J. Proteome Res. 15 (2016) 26582675. https://doi.org/10.1021/acs.jproteome.6b00217.

[72] G. Zancolli, L. Sanz, J.J. Calvete, W. Wüster, Venom On-a-Chip: A Fast and Efficient Method for Comparative Venomics, Toxins (Basel). 9 (2017). https://doi.org/10.3390/toxins9060179. 
[73] Z. Levy, A. Bdolah, Multiple molecular forms of snake venom phosphodiesterase from Vipera palastinae, Toxicon. 14 (1976) 389-390. https://doi.org/10.1016/0041-0101(76)90086-6.

[74] G.R. Philipps, Purification and characterization of phosphodiesterase I from Bothrops atrox, Biochim. Biophys. Acta. 432 (1976) 237-244. https://doi.org/10.1016/0005-2787(76)90165-9.

[75] N.M. Ibrahim, W.H. Salama, A.E.E. Hakim, Phosphodiesitrase activity of some Egyptian snake venoms: biochemical and immunological characteristics and effect on blood coagulation of phosphodiesterase enzyme from Naja nigricollis venom, J Chem Pharm Res. 8 (2016) 11.

[76] J.G. Zalatan, T.D. Fenn, A.T. Brunger, D. Herschlag, Struct rat and Functional Comparisons of Nucleotide Pyrophosphatase/Phosphodiesterase and Alkaline Ph sspl atase: Implications for Mechanism and Evolution, Biochemistry. 45 (2006) 9788- ^ðし? nttps://doi.org/10.1021/bi060847t.

[77] WHO, Snakebite envenoming - Key facts 2010, (2019). https://www.who.int/news-room/factsheets/detail/snakebite-envenoming (accessed A $\sim r_{1 i} ? 2,2020$ ).

[78] A.H. Laustsen, J. María Gutiérrez, C. Kı`dsen, K.H. Johansen, E. Bermúdez-Méndez, F.A. Cerni, J.A. Jürgensen, L. Ledsgaard, A. ^ 1o +os-Esteban, M. Øhlenschlæger, U. Pus, M.R. Andersen, B. Lomonte, M. Engmark, M.B. Pucca, '"ros and cons of different therapeutic antibody formats for recombinant antivenom developme nt, Toxicon. 146 (2018) 151-175. https://doi.org/10.1016/j. ${ }^{+}$ox. son. 2018.03.004.

[79] R.D. Bremel, E.J. $\mathrm{F}^{\top}$ 'ran, An integrated approach to epitope analysis I: Dimensional reduction, visualization and prediction of MHC binding using amino acid principal components and regression approaches, Immunome Res. 6 (2010) 7. https://doi.org/10.1186/1745-7580-6-7.

[80] G.N. Sivalingam, A.J. Shepherd, An analysis of B-cell epitope discontinuity, Molecular Immunology. 51 (2012) 304-309. https://doi.org/10.1016/j.molimm.2012.03.030.

[81] E. Oyama, N. Furudate, K. Senuki, H. Takahashi, Purification and characterization of a new platelet aggregation inhibitor with dissociative effect on ADP-induced platelet aggregation, from the venom of Protobothrops elegans (Sakishima-habu), Toxicon. 53 (2009) 706-712. 
https://doi.org/10.1016/j.toxicon.2009.02.016.

[82] S.P. Kunapuli, R.T. Dorsam, S. Kim, T.M. Quinton, Platelet purinergic receptors, Current Opinion in Pharmacology. 3 (2003) 175-180. https://doi.org/10.1016/S1471-4892(03)00007-9.

[83] G.F. King, Venoms as a platform for human drugs: translating toxins into therapeutics, Expert Opinion on Biological Therapy. 11 (2011) 1469-1484. https://doi.org/10.1517/14712598.2011.621940.

[84] K. de C.F. Bordon, C.T. Cologna, E.C. Fornari-Baldo, E.L. Pinheiro-Júnior, F.A. Cerni, F.G. Amorim, F.A.P. Anjolette, F.A. Cordeiro, G.A. Wiezel, I.A. Cardoso I.G. Ferreira, I.S. de Oliveira, J. Boldrini-França, M.B. Pucca, M.A. Baldo, E.C. Arantes, From Ani .la! 'olsons and Venoms to Medicines: Achievements, Challenges and Perspectives in Drug Disı overy, Front. Pharmacol. 11 (2020) 1132. https://doi.org/10.3389/fphar.2020.01132.

[85] S.E. Gasanov, M.A. Alsarraj, N.E. Gasanov, F - Rael, Cobra Venom Cytotoxin Free of Phospholipase A 2 and Its Effect on Model Memhra nes and T Leukemia Cells, Journal of Membrane Biology. 155 (1997) 133-142. https://doi.org/16. ${ }^{1007 / s 002329900165 . ~}$

[86] I.S. de Oliveira, R.V. Manzini, I. s. Terı eira, I.A. Cardoso, K. de C.F. Bordon, A.R.T. Machado, L.M.G. Antunes, J.C. Rosa, E.C. Ara tes, Cell migration inhibition activity of a non-RGD disintegrin from Crotalus durissus collilineatu venom, J Venom Anim Toxins Incl Trop Dis. 24 (2018) 28. https://doi.org/10.1186/s^04 19-0 :8-0167-6.

[87] D.A. Maria, R.C. Vas ,ão, I.R.G. Ruiz, Haematopoietic effects induced in mice by the snake venom toxin jararhagin, Toxicon. 42 (2003) 579-585. https://doi.org/10.1016/S0041-0101(03)00237$\mathrm{X}$.

[88] M.B. Pucca, S. Peigneur, C.T. Cologna, F.A. Cerni, K.F. Zoccal, K. de C.F. Bordon, L.H. Faccioli, J. Tytgat, E.C. Arantes, Electrophysiological characterization of the first Tityus serrulatus alpha-like toxin, Ts5: Evidence of a pro-inflammatory toxin on macrophages, Biochimie. 115 (2015) 8-16. https://doi.org/10.1016/j.biochi.2015.04.010.

[89] M.B. Pucca, S. Ahmadi, F.A. Cerni, L. Ledsgaard, C.V. Sørensen, F.T.S. McGeoghan, T. 
Stewart, E. Schoof, B. Lomonte, U. auf dem Keller, E.C. Arantes, F. Çalışkan, A.H. Laustsen, Unity Makes Strength: Exploring Intraspecies and Interspecies Toxin Synergism between Phospholipases A2 and Cytotoxins, Front. Pharmacol. 11 (2020) 611. https://doi.org/10.3389/fphar.2020.00611.

[90] S. Ahmadi, M.B. Pucca, J.A. Jürgensen, R. Janke, L. Ledsgaard, E.M. Schoof, C.V. Sørensen, F. Çalışkan, A.H. Laustsen, An in vitro methodology for discovering broadly-neutralizing monoclonal antibodies, Sci Rep. 10 (2020) 10765. https://doi.org/10.1038/s41598-020-67654-7.

[91] M. Rivel, D. Solano, M. Herrera, M. Vargas, M. Villalta, Á. Segura, A.S. Arias, G. León, J.M. Gutiérrez, Pathogenesis of dermonecrosis induced by venom of the ,p1 ing cobra, Naja nigricollis: An experimental study in mice, Toxicon. 119 (2016) 171-179.

https://doi.org/10.1016/j.toxicon.2016.06.006.

[92] G.D. Laing, P.B. Clissa, R.D.G. Theakston, A ^ Mourd-da-Silva, M.J. Taylor, Inflammatory

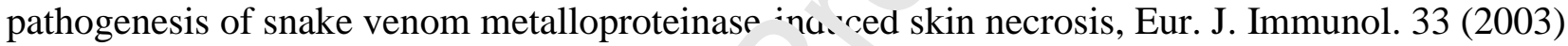
3458-3463. https://doi.org/10.1002/eji.2003244;5.

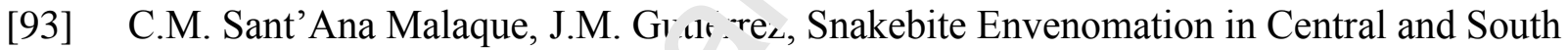
America, in: J. Brent, K. Burkhart, P. Dar §an, B. Hatten, B. Megarbane, R. Palmer (Eds.), Critical Care Toxicology, Springer Internationaı 'uulishing, Cham, 2015: pp. 1-22. https://doi.org/10.1007/978-3319-20790-2_146-1.

Table 1. Protein recovery from $C d c$ PDE during the purification steps.

\begin{tabular}{|c|c|c|c|c|c|c|c|}
\hline Sample & $\begin{array}{c}\text { Purification } \\
\text { Step }\end{array}$ & $\begin{array}{c}\text { Protein } \\
\text { recovery } \\
(\%) *\end{array}$ & $\begin{array}{c}\text { Total } \\
\text { protein } \\
\text { (mg) }\end{array}$ & $\begin{array}{c}\text { Total } \\
\text { activity } \\
\text { (U) }\end{array}$ & $\begin{array}{l}\text { Specific } \\
\text { activity } \\
\text { (U/mg) }\end{array}$ & $\begin{array}{c}\text { Purification } \\
\text { fator }\end{array}$ & $\begin{array}{c}\text { Yield } \\
(\%)\end{array}$ \\
\hline $\begin{array}{l}\text { Snake } \\
\text { venom }\end{array}$ & Supernatant & 100.00 & 90.00 & 125.10 & 1.39 & 1 & 100 \\
\hline
\end{tabular}


Gel

S3

2.87

2.58

68.89

27.09

19.49

55

filtration

Anion

A1

Exchange

0.83

0.75

106.49

141.99

102.15

85

Cation

C2

0.71

0.64

68.80

107.50

77.34

55

Exchange

*Recovery percentage calculated using Unicorn 5.2 software (GE He althcare) according to the ratio between the area under the absorbance curve at $280 \mathrm{~nm}$ of each corl esp nding fraction and the sum of the areas of all fractions eluted. One unit of enzymatic activity ( I) cr rresponds to an increase of 1.0 $\mathrm{Abs}_{400 \mathrm{~nm}} / \mathrm{min}$.

Figure 1. Chromatographic and enzymatic ...tiv ${ }^{+}$v profiles of the venom and fractions using an FPLC system. (A) $C d c$ venom (90 mg) was fiı 'red on a HiPrep Sephacryl S-200 HR column $(16 \times$ $600 \mathrm{~mm}, 47 \mu \mathrm{m}$ particles), using isocrati : f, $\mathrm{d}_{1} \mathrm{ent}$ of $50 \mathrm{mM}$ Tris- $\mathrm{HCl}$ containing $150 \mathrm{mM} \mathrm{NaCl}, \mathrm{pH} 8$, at a flow rate of $0.5 \mathrm{~mL} / \mathrm{min}$. Inset p. nel - whole chromatographic profile without magnification. (B) Anion exchange chromatography of fraction S3 (6 mg) on a HiTrap ANX (high sub) FF column $(16 \times$ $25 \mathrm{~mm})$, using a linear $\mathrm{g}_{1}$ dl $\left.n \mathrm{nt}, 0-100 \%\right)$ of buffer $\mathrm{B}(50 \mathrm{mM}$ Tris- $\mathrm{HCl}$ with $1 \mathrm{M} \mathrm{NaCl}, \mathrm{pH} 8$, dashed blue line), at a flow rate or $\lrcorner \mathrm{mL} / \mathrm{min}$. Buffer $\mathrm{A}$ is $50 \mathrm{mM}$ Tris-HCl, $\mathrm{pH}$ 8. (C) Cation ion-exchange chromatography of fraction A1 $(0.7 \mathrm{mg})$ on a carboxymethyl cellulose-52 column $(10 \times 100 \mathrm{~mm})$, using a segmented concentration gradient (0-100\%) of buffer B (50 mM sodium acetate with $1 \mathrm{M}$ $\mathrm{NaCl}, \mathrm{pH} 5$, dashed blue line), at a flow rate of $0.5 \mathrm{~mL} / \mathrm{min}$. Buffer $\mathrm{A}$ is $50 \mathrm{mM}$ sodium acetate, $\mathrm{pH} 5$. (D) Reversed-phase chromatography of fraction C2 (1 mg) on a C4 Jupiter column $(4.6 \times 250 \mathrm{~mm}, 300$ $\AA$ A $5 \mu \mathrm{m}$ particles), using a linear gradient (0-100\%) of solution B (80\% acetonitrile, in $0.1 \%$ TFA, 
dashed blue line), at a flow rate of $1 \mathrm{~mL} / \mathrm{min}$. Solution A is $0.1 \%$ TFA. Pink vertical lines represent relative $C d c \mathrm{PDE}$ activity of fractions $(50 \mu \mathrm{L})$ using bis(p-nitrophenyl) phosphate substrate.

Figure 2. Electrophoretic profile and mass determination of $C d c P D E$ at different conditions. SDS-PAGE (10\%) under (A) non-reducing and (B) reducing conditions. (C) Evaluation of CdcPDE Nglycosylation. M1: Molecular mass marker (97.0-14.4 kDa); M2: Wide range molecular mass marker (120-10 kDa); SV: C. d. collilineatus venom; S3, A1 and C2: Fractions obtained, respectively, in the first, second, and third chromatographic step; R: Fraction cbtained through reversed-phase chromatography; Black arrow indicates PNGase enzyme; PDE PDE $E_{\mathrm{r}}$ : reduced $C d c$ PDE. (D) Mass spectrum of $C d c$ PDE obt: inec by MALDI-TOF (positive linear mode) using sinapinic acid (SA) matrix.

Figure 3. PDE activity assays. The substrate bis(p-nitıphenyl) phosphate $(1 \mathrm{mM})$ was added to a mixture $(150 \mu \mathrm{L})$ of $C d c \mathrm{PDE}(0.175 \mu \mathrm{g})$ and $1^{\mathrm{n}} \mathrm{n}$. M Tris- $\mathrm{HCl}, \mathrm{pH} 8$, previously incubated for $10 \mathrm{~min}$ at $37^{\circ} \mathrm{C}$. This new mixture was incubated for $3 \mathrm{mins}$ at $37^{\circ} \mathrm{C}$. The reaction was stopped with $50 \mathrm{mM}$ sodium hydroxide $(\mathrm{NaOH})$. Absorbanre vas measured at $400 \mathrm{~nm}$. The enzymatic activity was expressed as a percentage of relativ: activity to that of highest absorbance. The values represent the mean \pm standard deviation ( $\mathrm{SD}, \mathrm{n}-3$ ). (A) $\mathrm{pH}$ profile. The enzymatic activity assay was performed by incubating $C d c \mathrm{PDE}$ and sul strai 2 in $100 \mathrm{mM}$ Tris- $\mathrm{HCl}$ buffers at different pHs for $30 \mathrm{~min}$, at $37^{\circ} \mathrm{C}$. (B) Storage temperature prof.le. The enzymatic activity assay was performed with $C d c P D E$ previously stored at different temperatures for 1 hour. (C) Temperature profile. The enzymatic activity assay was performed by incubating $C d c \mathrm{PDE}$ and substrate in $100 \mathrm{mM}$ Tris- $\mathrm{HCl}(\mathrm{pH} 8)$ at different temperatures for 30 min. (D) Michaelis-Menten fitting for $C d c \operatorname{PDE}(5 \mu \mathrm{g}, 0.537 \mathrm{U}, 5 \mu \mathrm{M})$ kinetics curve, using the substrate bis(p-nitrophenyl) phosphate. (E) $C d c$ PDE and different inhibitors $(0.625-10 \mathrm{mM})$ were previously incubated for $30 \mathrm{~min}$ at $37^{\circ} \mathrm{C}$. As a positive control (without inhibitor), PDE was previously incubated only with buffer (100 mM Tris-HCl, $\mathrm{pH} 8)$. 
Figure 4. PDE thermal stability. $C d c \operatorname{PDE}(2 \mu \mathrm{g})$ was incubated with water and different $50 \mathrm{mM}$ buffering conditions (sodium acetate, $\mathrm{pH}$ 4.5; sodium citrate, $\mathrm{pH}$ 5; succinate, $\mathrm{pH}$ 5.5; MES, $\mathrm{pH}$ 6; bisTris, $\mathrm{pH}$ 6.5; imidazole, $\mathrm{pH}$ 7; 4-(2-hydroxyethyl)-1-piperazineethanesulfonic acid (HEPES), pH 7.5; Tris-HCl, $\mathrm{pH} \mathrm{8;} \mathrm{bis-Tris} \mathrm{propane,} \mathrm{pH} 8.5$; 2-amino-2-methyl-1,3-propanediol (AMPD), $\mathrm{pH} 9$; and glycine, $\mathrm{pH}$ 9.5), containing different $\mathrm{NaCl}$ concentrations $(0-1000 \mathrm{mM})$. The fluorescent Sypro Orange (50x) was added to the samples. Thermal denaturation was evaluated at a temperature ranging from $25{ }^{\circ} \mathrm{C}$ to $95{ }^{\circ} \mathrm{C}$, with gradual increases of $1{ }^{\circ} \mathrm{C} / \mathrm{min}$, followed 'jy fluorescence reading using the excitation/emission wavelength of 492/610 nm in the real time ther 10c. cler Mx3005P.

Figure 5. Sequence alignment of $\boldsymbol{C d c P D E}$ and others snake $\backslash$ eno n PDEs. $C d c \mathrm{PDE}, C$. adamanteus (J3SEZ3 and J3SBP3), Protobothrops flavoviridis (T2HI 62), and Macrovipera lebetina (W8E7D1). Instead of the conserved residues, the following fer'mes are highlighted due to high identity: Low consensus amino acid residues (pink), signal $\ldots+t^{\prime}$ (gray), Cys residues (yellow), Asn-aaX-Ser/Thr residues, which represent the potential N-glyce ylation sites (blue); and Asn-aaX-Ser/Thr residues, which represent $\mathrm{N}$-glycosylation sites det $/$ mined by MS/MS (green). Based on other snake venom PDE sequences, residue Thr (163), cu'oreci in red, potentially participates in catalytic activity.

Figure 6. Molecular modeling of racPDE and docking simulation. (A) Front and (B) back view of $C d c$ PDE; 3D-structure $c^{f}$ th.$m$ lecule was estimated by Swiss-Model using the PDE from Taiwan cobra (Naja atra; PDB: $5 \mathrm{C}^{\boldsymbol{7}}$ ) as a template. Disulfide bonds are shown in yellow, $\alpha$-helices in red, $\beta$ sheets in blue, and N-terminal amino acid residues in the pink segment. The residue (T163) that may participate in $C d c \mathrm{PDE}$ activity is highlighted. (C) Docking simulation with bis(p-nitrophenyl) phosphate substrate (blue, orange, and red molecule; PubChem CID: 255). (D) Magnified view and (E) substrate-enzyme interaction.

Figure 7. $C d c$ PDE recognition by anticrotalid antivenom in ELISA and prediction of the recognized epitopes. (A) $C d c \mathrm{PDE}$ and $C$. $d$. collilineatus venom $(2 \mu \mathrm{g}$ each) were incubated with commercial anti-crotalid antivenom from Instituto Butantan. Absorbance was measured at $490 \mathrm{~nm}$. 
Data are presented as mean $\pm \mathrm{SD}$ analyzed by one-way ANOVA and Tukey's multiple comparison test (quadruplicate assay). $\mathrm{C}(+)$ : wells coated with non-immunized horse serum diluted 1:50; SV: C. $d$. collilineatus venom incubated with commercial anti-crotalid antivenom diluted 1:100; C(-) SV: C. d. collilineatus venom incubated with non-immunized horse serum diluted 1:100; PDE: $C d c$ PDE incubated with commercial anti-crotalid antivenom diluted 1:100; C(-) PDE: $C d c$ PDE incubated with non-immunized horse serum diluted 1:100. $* * * * p<0.0001$ when compared to its negative control; \#\#\# $p<0.001$ when compared to positive control; ${ }^{\# \# \#} p<0.0001$ when compared to positive control. (B) $C d c \mathrm{PDE}$ sequence with the epitopes predicted by ABCpred Server + jor highlighted in blue.

Figure 8. Functional assays with $\boldsymbol{C d c P D E}$. (A) Inhibition o. AL P-induced platelet aggregation by $C d c$ PDE. Different concentrations of $C d c$ PDE $\left(15-120 \mu \mathrm{\varepsilon} \mathrm{m}_{\llcorner} \quad j 0 \mu \mathrm{L}\right)$ were incubated with PRP (450 $\mu \mathrm{L})$ at $37{ }^{\circ} \mathrm{C}$ for 5 min under shaking. Then, $\mathrm{AD}^{\mathrm{D}}(2.4 \mu \mathrm{M})$ was added to the mixture and the aggregation was monitored for $6 \mathrm{~min} . \mathrm{C}(-)$ : wa $\mathrm{a}^{+\sim r}$. $* * * p<0.0001$ when compared to negative control. (B) Effect of $C d c \mathrm{PDE}$ on N/TERT cell via ility. N/TERT cells were incubated with different concentrations of $C d c$ PDE (10-200 $\mu \mathrm{g} / \mathrm{m} L$ in DMEM medium. After $24 \mathrm{~h}$, cell viability was measured by using CellTiter-Glo luminescent $c \cdot 11$ viability assay. $* * * * p<0.0001$ when compared with negative control (cells incubated with salint coration) and the presented values are the mean \pm SD $(n=3)$. 


\section{Figure 1}

A

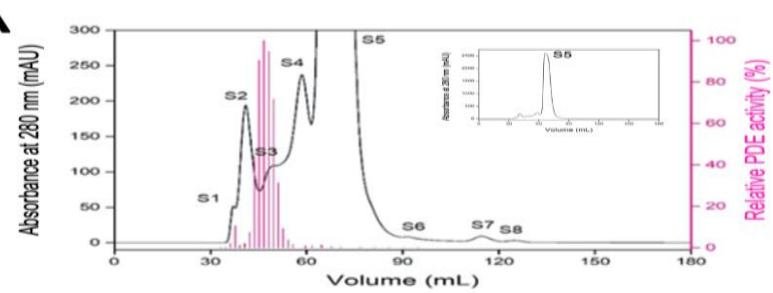

c

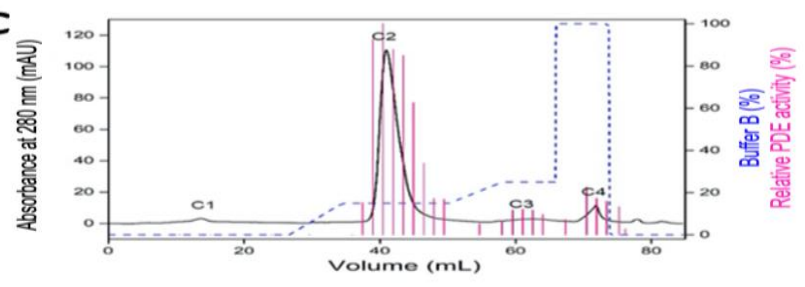

B

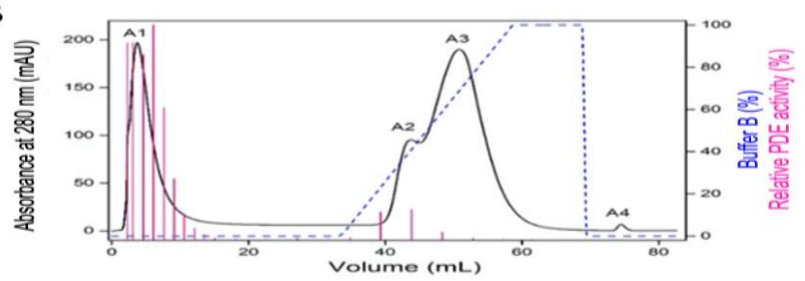

D

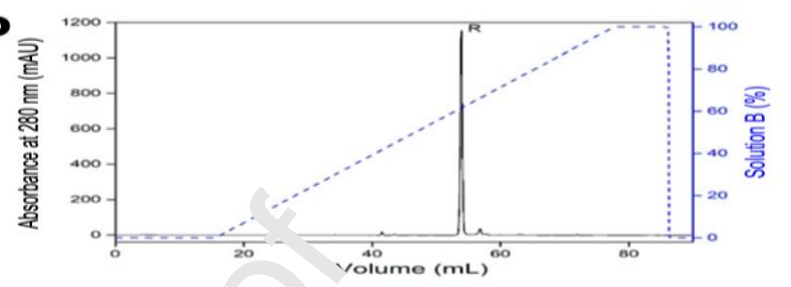

Figure 2
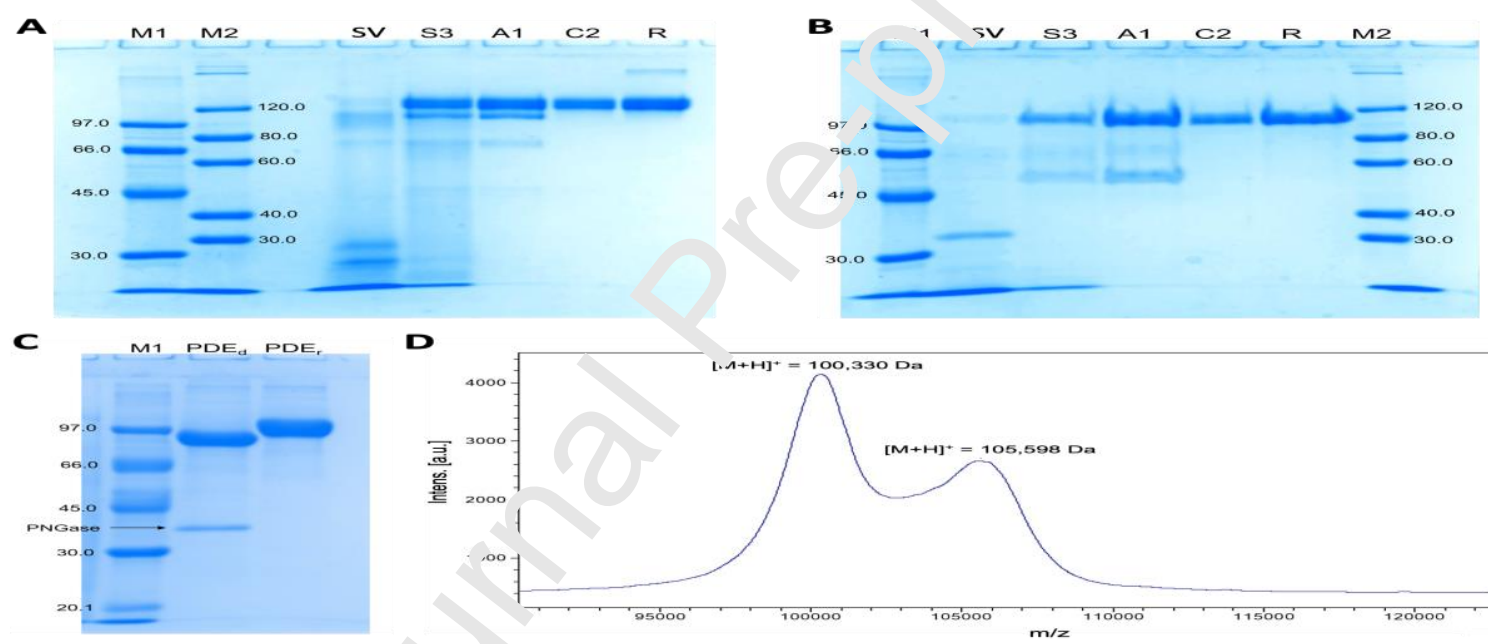

c

D

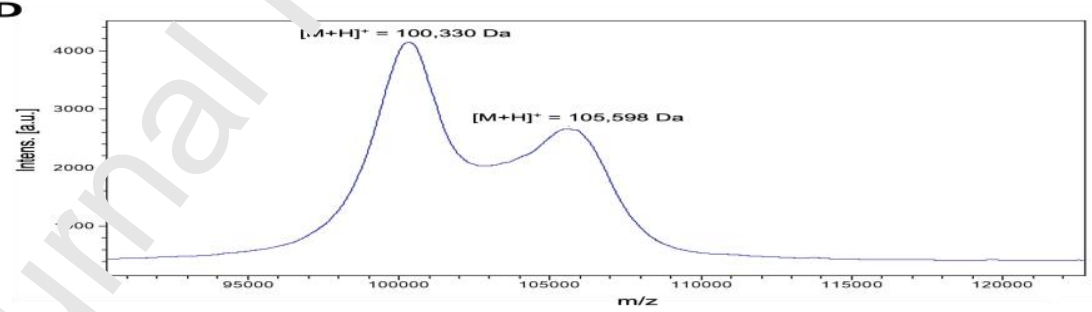

Figure 3
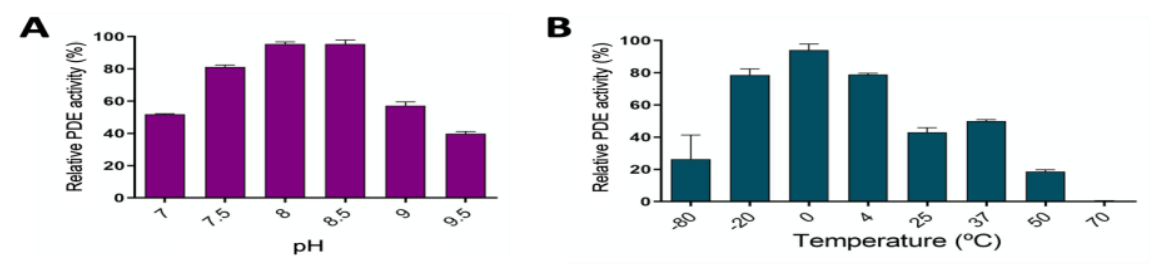

C

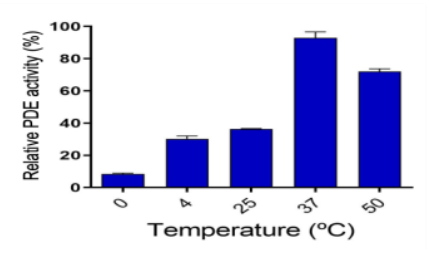

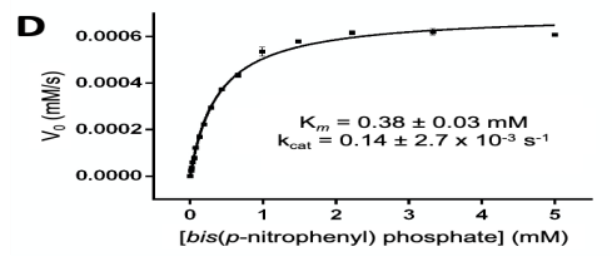

E

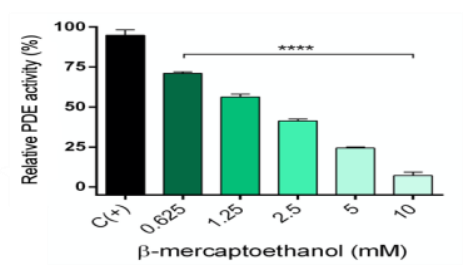


Figure 4

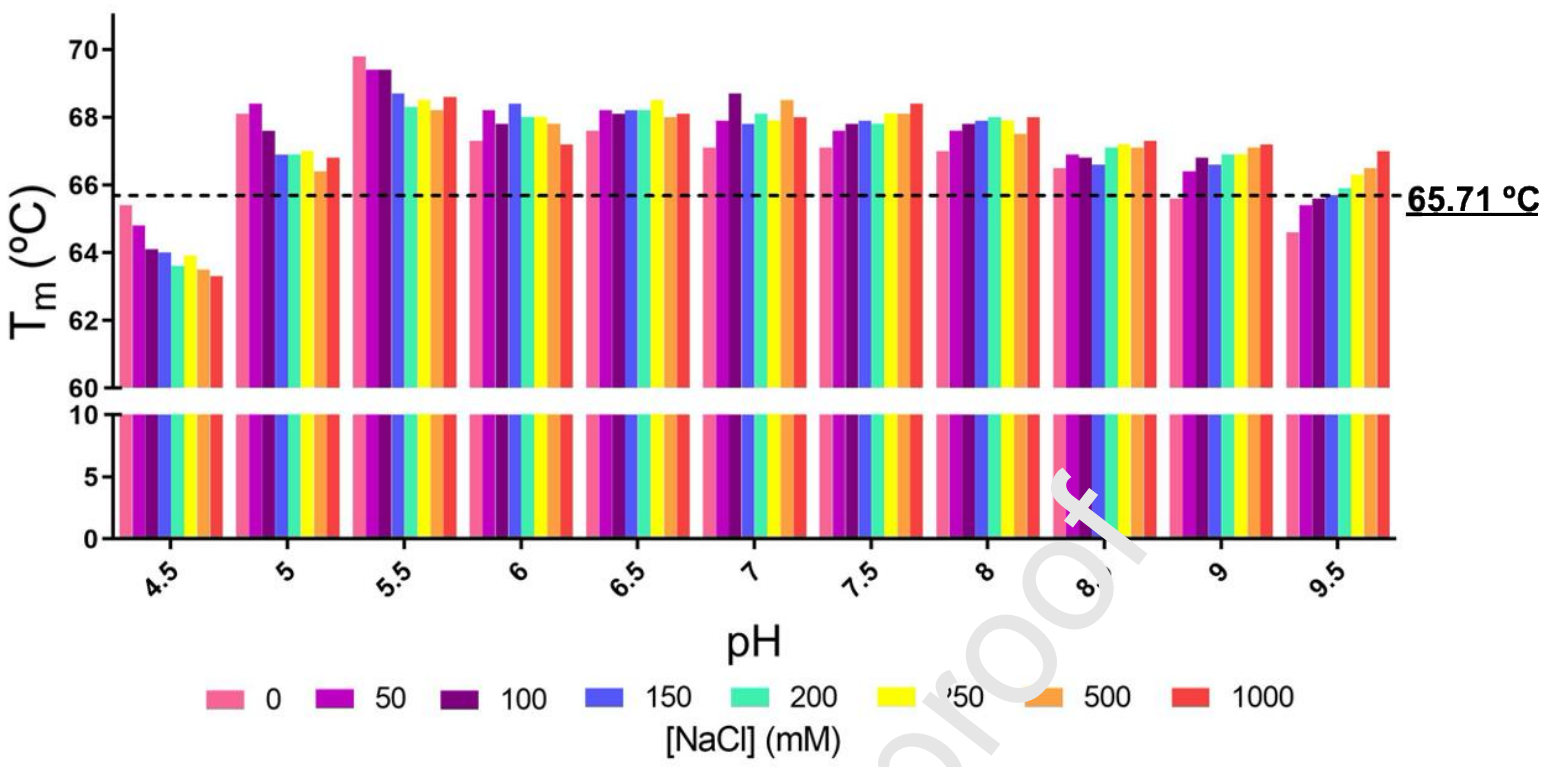

Figure 5

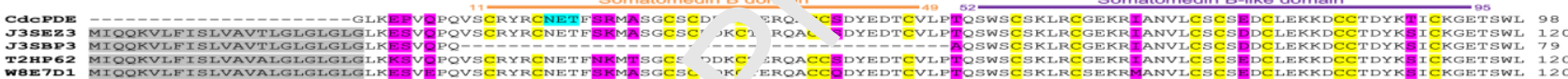

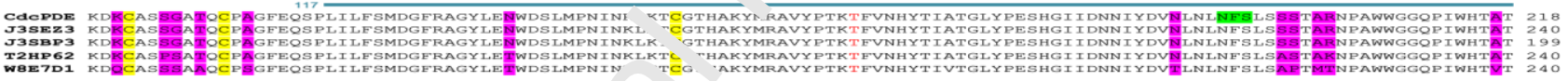

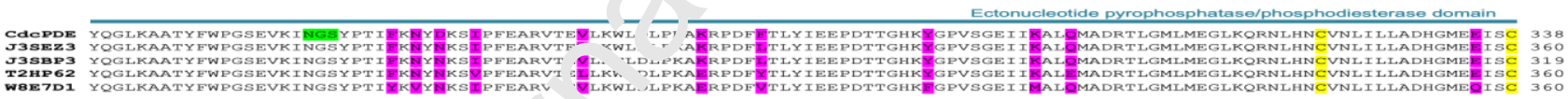

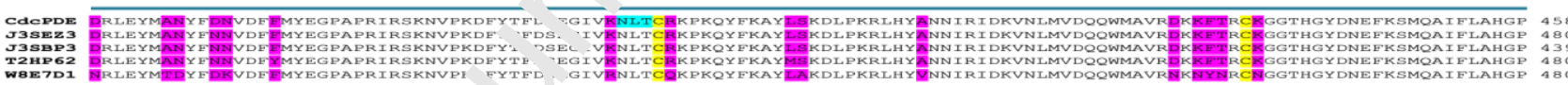

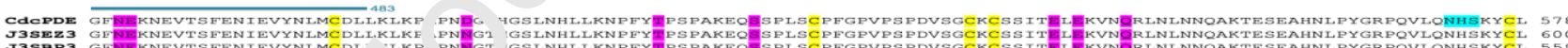

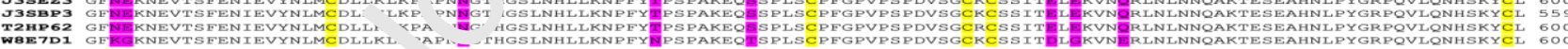

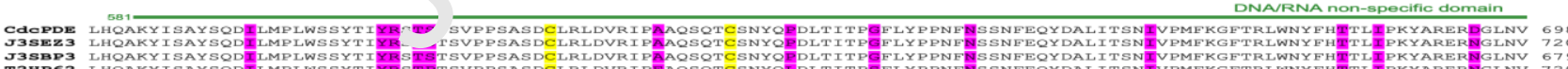

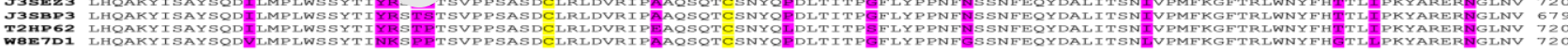

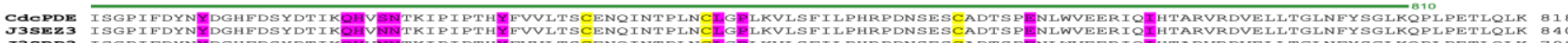

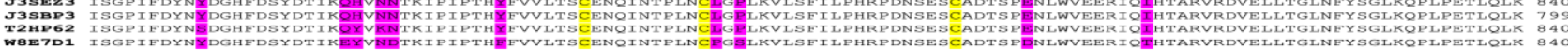

CACPDE TFIPIFUNPYN 829 Identity

$\begin{array}{lll}\text { J3SEZ3 TFLPIFVNPVN } 829 & 10.8 \\ \text { J33BP3 TFLPIFVNPVN } 810 & 98.8\end{array}$

$\begin{array}{lll}\text { T2HP62 TFLPIFVNPVN } 851 & 96: 3 \\ \text { WBE7D1 TELPEVNPVN } 851 & 91.9\end{array}$ 
Figure 6
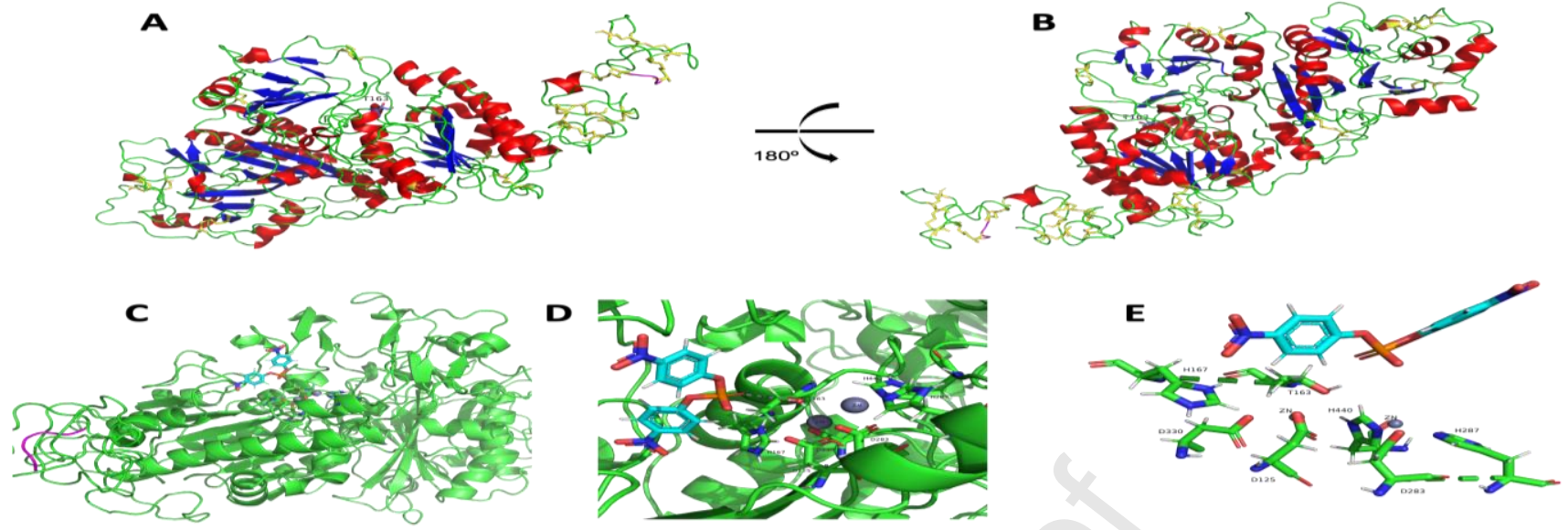

\section{Figure 7}

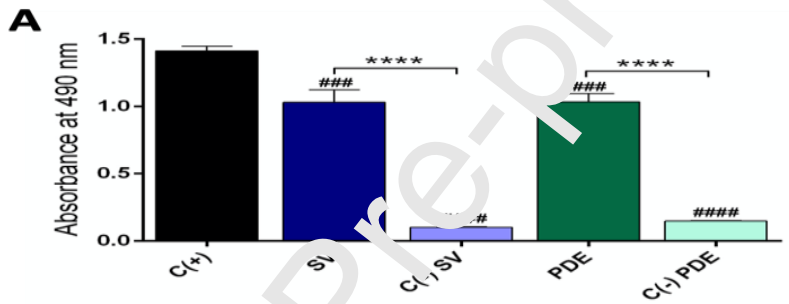

B

GLKEPVQPQVSCRYRCNETFSRMASGCSCDDKC TERQACCSDYEDTCVLPTQSWSCSKLRCGEKRIANVLCS CSEDCLEKKDCCTDYKTICKGETSWLKL 'CASSGATQCPAGFEQSPLILFSMDGFRAGYLENWDSLMPNINK

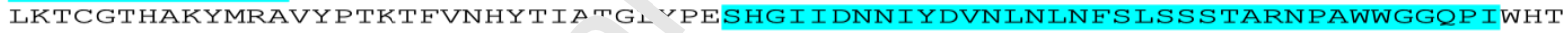
ATYQGLKAATYFWPGSEVKINGSYPT IF, VYDKSIPFEARVTEVLKWLDLPKAKRPDFFTLYIEEPDTTGHK YGPVSGEIIKALQMADRTLGMLMEGLK 2R JLHNCVNLILLADHGMEEISCDRLEYMANYFDNVDFFMYEGPA PRIRSKNVPKDFYTFDSEGIVKNI $\perp$ 'R _. KQYFKAYLSKDLPKRLHYANNIRIDKVNLMVDQQWMAVRDKKF TRCKGGTHGYDNEFKSMQAIFLF "GPC ?NEKNEVTSFENIEVYNLMCDLLKLKPAPNDGTHGSLNHLLKNPF YTPSPAKEQSSPLSCPFGPVPS $2 D$ 'SGCKCSSITELEKVNQRLNLNNQAKTESEAHNLPYGRPQVLQNHSKY CLLHQAKYISAYSODILMPLWS TYTIYRSTSTSVPPSASDCLRLDVRIPAAQSOTCSNYQPDLTITPGFLYP PNFNSSNFEQYDALITSNIVE UFI GFTRLWNYFHTTLIPKYARERDGLNVISGPIFDYNYDGHFDSYDTIKQ HVSNTKIPIPTHYFVVLTSCEN INTPLNCLGPLKVLSFILPHRPDNSESCADTSPENLWVEERIQIHTARV RDVELLTGLNFYSGLKQPLト ᄀT

\section{Figure 8}

A

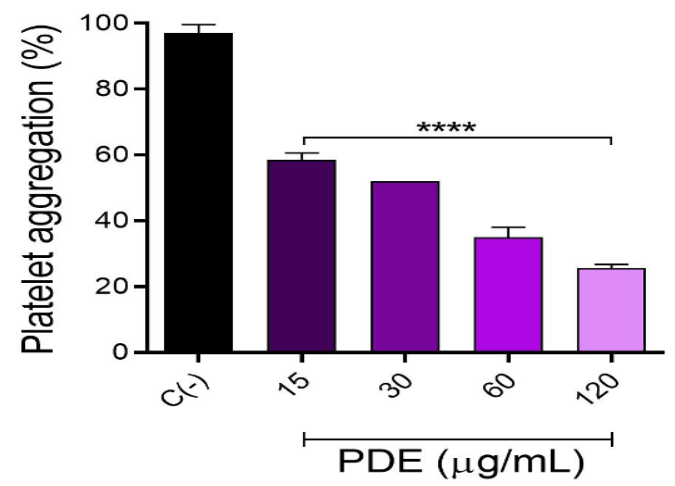

B

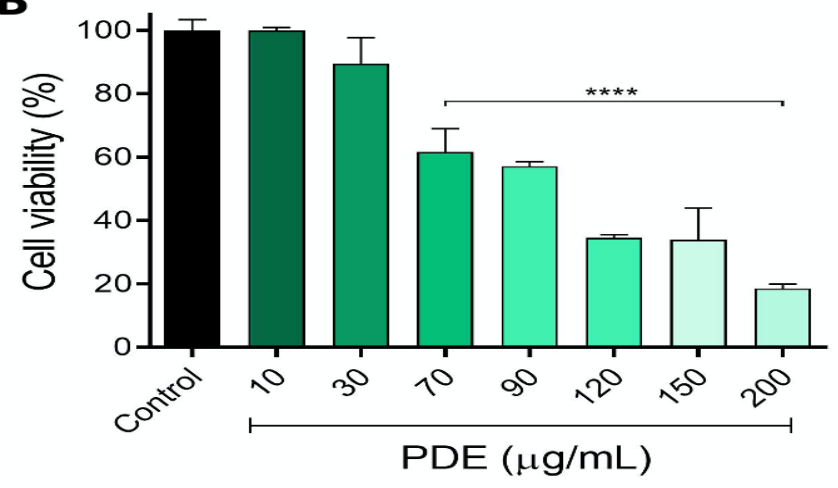




\section{Journal Pre-proof}

\section{Highlights}

- $\quad C d c \mathrm{PDE}$ is the first phosphodiesterase isolated from $C . d$. collilineatus snake venom;

- Metal ions and disulfide bonds are essential for its enzymatic activity;

- Crotalid antivenom is able to recognize $C d c \mathrm{PDE}$;

- $\quad C d c P D E$ inhibits platelet ADP-induced aggregation;

- $C d c \mathrm{PDE}$ is cytotoxic to human keratinocytes. 